\title{
Prosthetic Impingement in Total Hip Arthroplasty-The Trigger for Adverse Wear
}

\author{
Ian C. Clarke', Jean Yves Lazennec ${ }^{2}$, Evert Johannes Smith ${ }^{3}$, Thomas K. Donaldson ${ }^{1}$ \\ ${ }^{1}$ Department of Orthopaedics, Loma Linda University Medical Center, Loma Linda, CA, USA \\ ${ }^{2}$ Department of Orthopaedics, La Pitié-Salpêtrière University Hospital, Paris, France \\ ${ }^{3}$ Spire Bristol Hospital, Bristol, UK \\ Email: ithipgeek15@yahoo.com
}

How to cite this paper: Clarke, I.C., Lazennec, J.Y., Smith, E.J. and Donaldson, T.K. (2020) Prosthetic Impingement in Total Hip Arthroplasty-The Trigger for Adverse Wear. Open Journal of Orthopedics, 10, 321-358. https://doi.org/10.4236/ojo.2020.1012033

Received: October 19, 2020

Accepted: December 4, 2020

Published: December 7, 2020

Copyright $\odot 2020$ by author(s) and Scientific Research Publishing Inc. This work is licensed under the Creative Commons Attribution International License (CC BY 4.0).

http://creativecommons.org/licenses/by/4.0/

\section{(c) (i) Open Access}

\begin{abstract}
Development of total hip arthroplasty (THA) now spans more than 5 decades encompassing combinations of metal-on-metal (MOM), ceramic-on-metal (COM), metal-on-plastic (MOP), ceramic-on-plastic (COM), and ceramic-on-ceramic (COC). In every arena of extensive technical development, there exists a data set that when viewed in isolation seemed of little import, but when assembled in-toto may produce a generational shift in perception. Our review focused on two such THA events. Firstly, COC retrieval studies (1999-2001) noted habitual wear patterns on heads and peripheral wear stripes, along with femoral-neck impingement, and ceramic surfaces stained gray by metal debris. These COC data indicated THA risks included, 1) cup edge-loading (E/L) on heads producing "stripe wear", 2) component impingement releasing metal particles resulting in 3) tissues contaminated by metal debris. A corresponding MOM impingement-debris mechanism was only perceived by Howie (2005) in a McKee-Farrar retrieval study. Our anticipation at LLUMC was that MOM retrievals would provide superior wear details to those seen on COC retrievals. We noted stripe wear in the polar zone of CoCr heads and basal stripes in the non-wear areas. The basal-polar stripe combinations were found in all MOM retrievals. Basal-polar stripe combinations followed cup-rim profiles in our LLUMC simulations of prosthetic impingement. LPUH videos demonstrated the formation of stripe wear in functional-standing and functional-sitting postures for both impingement and subluxation episodes using THA and RA designs. The stripes on $\mathrm{CoCr}$ heads revealed the large scratches we now term "microgrooves". Microgroove width varied from 40 - 400 um with 100 um being typical. The longitudinal striations in microgrooves, the raised jagged lips, scratches with shallow entry and exit termini, were all indicative of a classic $3^{\text {rd }}$-body wear mechanism. The THA impingement simulations denoted four sites of edge-loading, i.e.
\end{abstract}


neck-E/L, inferior cup-E/L, superior cup-E/l and head-E/L, and ingress of Ti64 particles as a contaminating-roughness effect. Individual MOM cases referred to LLUMC demonstrated dramatic evidence of neck notching. At one end of the debris spectrum, a Ti64-notch model predicting a $6 \mathrm{~mm}^{3}$ annual wear-rate represented the release of 5700 particles of 126 um-size (approximating daily release of 16 particles). At the other end of the spectrum, if metal particles were crushed between MOM surfaces to the equivalent nanometer size found in tissues, our notch model represented approximately 22 -trillion Ti64 particles annually deposited in tissues. The anatomical THA models represented in LPUH videos demonstrated that even 1-degree of head subluxation from a rigid cup created a cup "lift-off" scenario (CLO) that would open a gap of 250 - 400 microns between femoral head and cup. This would void all lubrication potential and focus the total hip-joint force along the beveled cup rim, i.e. stripe wear. It is therefore interesting that MOM impingement/debris predictions by Howie et al. have not been confirmed until now or discussed in contemporary literature. Therefore, this review of 50 years of THA data demonstrated that hip impingement was always the trigger for adverse wear and that metal-backed cups represent the potential for release of metal debris at extremes of functional standing and sitting postures.

\section{Keywords}

Ceramic on Ceramic, Edge-Loading, Impingement, Metal Debris, Metal on Metal, Metal on Polyethylene, Resurfacing Arthroplasty, Retrieval, Stripe Wear, Subluxation, Total Hip Arthroplasty, $3^{\text {rd }}$-Body Wear

\section{Introduction}

Considerable endeavor has gone into understanding wear-related risks in total hip arthroplasty (THA). Nevertheless, impingement of artificial hip components as a potential failure mechanism has received scant attention. The purpose of this paper is to assemble information that will demonstrate; 1) prosthetic hip impingement is commonplace in THA patients, 2) "stripe" wear is a hallmark indicator for impingement, 3) "prosthetic" impingement risks damage to metallic neck and head, 4) edge-loading during impingement releases metal particles, and 5) retrieval evidence will demonstrate that large metal particles contaminate all arthroplasty types particularly those incorporating metal-backed acetabular cups.

Hip joints may impinge at many locations in functional activities, depending on positioning of spine, pelvis and limbs. We shall assess hip-impingement risks by assembling information from COC, MOM, and MOP retrieval studies. This review begins with ceramic bearings used in THA. Ceramic heads are particularly suited to visualizing contamination by metal debris and also demonstrate a novel form of surface damage termed "stripe" wear [1] [2] [3] [4]. Compilation of evidence will show that stripe wear is a hallmark descriptor for THA im- 
pingement. We shall prove that stripe wear can be found on MOM bearings made of cobalt-chromium alloy ( $\mathrm{CoCr}$ ). We shall also examine MOP retrievals to ascertain if there is support for our governing hypothesis, that "prosthetic" impingement (2-body abrasive wear) is the trigger for 1) releasing metal particles (2-body abrasive wear), with 2) hip motion driving metal particles into the joint space, and 3) thereby promoting adverse $3^{\text {rd }}$-body wear.

\section{Pioneering Ceramic-on-Ceramic (THA 1970-1990)}

Pioneering THA of the 1960-1970 era (Figure 1) are well represented by cemented MOM designs of McKee-Farrar [5] (monolithic $\mathrm{CoCr}$ ), the non-cemented COC designs of Griss [6] [7] and Mittelmeier [8] and the cemented COC designs of Boutin [9]. Fixation of the cemented alumina cups proved problematic. In hindsight, it was component loosening that facilitated the earliest retrieval studies. Ceramic-head retrievals demonstrated linear surface damage termed "stripe" wear [3] [6]. Dorlot et al. studied wear on 20 COC retrieved CEM-cups, [2] noting that normal alumina wear patterns represented 0.2 um surface loss even after many years of use. In contrast, stripe damage was termed as "gross surface disruption". Dorlot et al. [1] described "gross wear tracks" 180 um deep and some quite lengthy (70 - $110 \mathrm{~mm}$ arcs). Nevelos et al. [10] focused on stripe damage as produced in "Autophor" [11] cases (Figure 1(b), Figure 1(c)). Component loosening was again the main reason for revision. The authors confirmed that stripe wear represented severe surface disruption (up to 150 um deep) within sharply-defined, well-polished surfaces. The consensus was that the cup rims produced high contact-stresses on femoral heads (edge-loading) during hip-extension and flexion activities. Similar to Dorlot et al., the authors identified metallic staining due to $\mathrm{CoCr}$ particles transferred from Autophor stems (Figure 1(b)).

LLUMC [12] [13] [14] [15] [16] analyzed three Autophor retrievals with up to 24 years follow-up (Figure 2(a)). Three wear areas were mapped (Figure 2(b)),

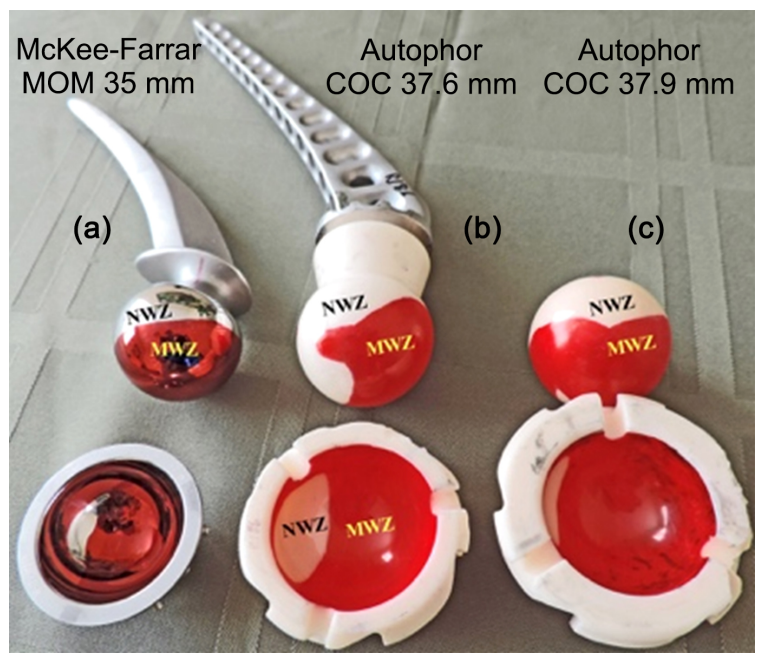

Figure 1. CEM-MOM and NC-COC (wear patterns colored red). 


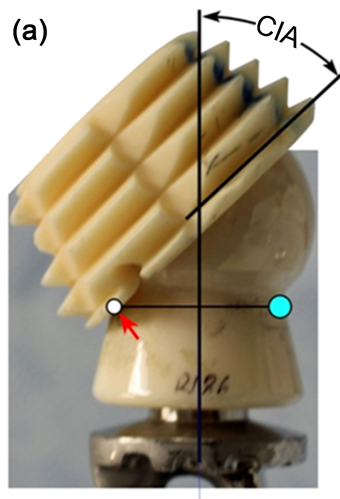

(b)

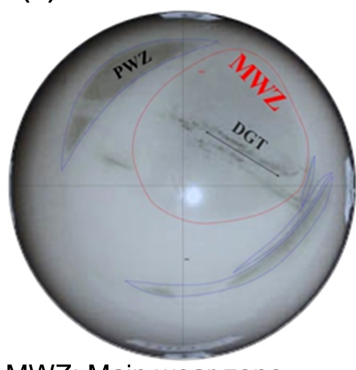

MWZ: Main wear zone

PWZ: peripheral wear zones DGT: dark gray track

(c)

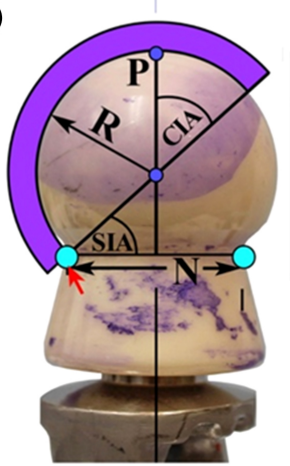

(d)

$\mathrm{H}: \mathrm{N}$ ratio $=1.36$ stripe $\mathrm{SIA}=42^{\circ}$ $\operatorname{cup} \mathrm{CIA}=48^{\circ}$

motion $\mathrm{ROM}=84^{\circ}$

Figure 2. Autophor COC design, (a) cup-on-neck impingement, (b) head retrieval [12], (c) CIA inclination [58], and SIA [23], (d) ROM algorithm.

1) main wear zones (MWZ) were smoothly polished (grade\# IV: grain pull-out/ pitting, 2) peripheral wear zones (PWZ) had rougher surfaces (grade V: severely disrupted surfaces), while 3) transition wear zones (TWZ) showed only slightly roughened surfaces (grade-III: polished, pitting). Femoral components also demonstrated edge-loading (neck-E/L) due to anterosuperior and inferoposterior impingement (Figure 2(a), Figure 2(c)). Cup rims showed edge-loading anterosuperiorly and posteroinferiorly. Stripe lengths varied from $16-79 \mathrm{~mm}$ and it was noted that in $90^{\circ}$ flexion the head stripes formed by combined retroversion of cup on head crossed the head's polar region in the posterior direction. These ceramic studies confirmed 1) stripe wear on heads (head-E/L), 2) cup-E/L, 3) impingement damage on femoral necks (neck-E/L), and 4) metallic staining as confirmation of circulating metal debris. It was noted that wear stripes on retrievals of contemporary THA appeared identical to the early reports, indicating that stripes were a normal occurrence in COC [16] [17].

Stripe-wear patterns can be readily visualized with reference to THA models and video simulations from La Pitié-Salpêtrière University Hospital (LPUH) that accompany this report (Appendix). Hip range-of-motion (ROM) is blocked when the cup impinges against the femoral neck (Figure 2(a), Figure 2(c)). Our $36 \mathrm{~mm}$ COC impingement model (Figure 3) simulates cup-rim profiles across the head for various hip positions. The $10 \mathrm{~mm}$ neck provides a head:neck ratio of 3.6, with the ROM-algorithm predicting $148^{\circ}$ of motion (Figure 2(d)). From 
a lateral view of posterior-impingement (Figure 3(a), Figure 3(b)), the black stripe begins at the posterolateral margin and traversing anteriorly crosses the polar region (MWZ) in the anteromedial quadrant to meet tangentially with the polar-circle (Figure 3(c): PC). The stripe in this model has a $16.1^{\circ}$ inclination (see Figure 2(c): CIA). Crossing the MWZ (Figure 3(d)), the black stripe re-enters the posterior quadrant and traverses in posteroinferior direction. For comparison, the red stripe (Figure $3(\mathrm{~d})$ ) represents cup profile with impingement in hip flexion. These stripes are mirror images due to lack of simulated anatomy and component positioning.

A realistic assessment of THA impingement is available in video downloads from LPUH (Appendix). The videos depict anatomical component positioning in "functional-standing" and "functional-sitting" postures. In video-1, the femoral-head and neck represent a THA (left hip-joint) with green and purple head quadrants signifying anterosuperior and anteroinferior facets, respectively. The femoral neck is a gray cylindrical representation that allows for both THA $\left(15^{\circ}\right.$ anteversion, head-neck ratio 2.5$)$ and RA designs. The $1^{\text {st }}$ video segment depicts frontal and lateral views of cup on left and right sides of the screen, respectively. Hip abduction of $36^{\circ}$ is depicted in a "functional-standing" posture. With hip-extension, the femoral neck impinges on the posteroinferior cup rim (lateral view), creating edge-loading on its posterior facet. Note the black stripe appearing at the contra-rim site indicating anterosuperior edge-loading on the head.

The $2^{\text {nd }}$ segment of video- 1 also in functional-standing posture depicts posterior impingement from the perspective of inferior and superior cup views (left and right sides of screen, respectively). As before, the inferior view shows neck impingement on the posteroinferior cup rim and the black head stripe traverses from posteroinferior to anterosuperior.
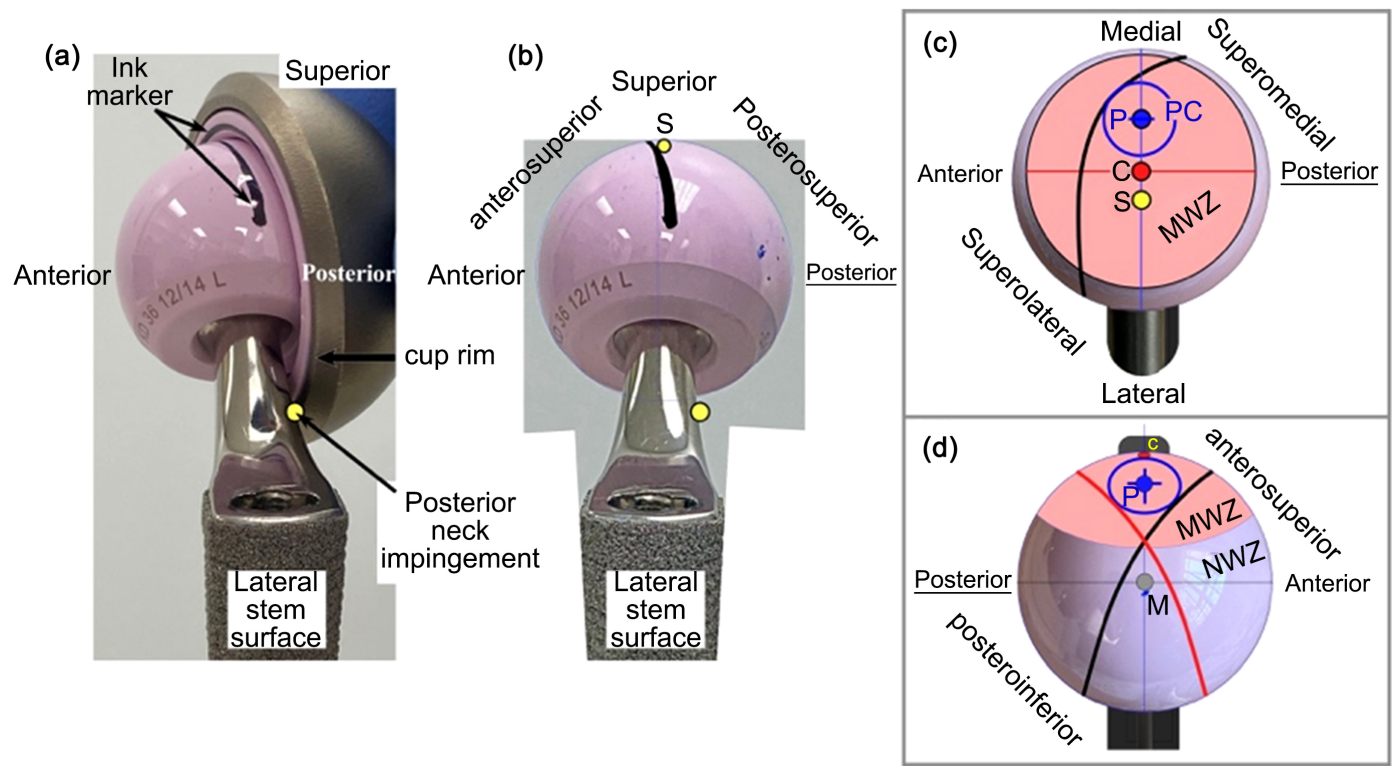

Figure 3. $36 \mathrm{~mm}$ THA model, (a) posterior impingement (left hip), (b) “anteverted" black stripe, (c) centroidal-axis view, (d) medial-axis view with black "anteverted" and red "retroverted" stripes. 
Video-2 depicts "functional-sitting" posture showing the same two segments and pelvic views as video-1. In hip flexion, the neck impinges on the anterosuperior cup rim creating edge-loading on its anterior facet. Note the red stripe representing cup-rim profile corresponding to posteroinferior edge-loading on the head. This stripe corresponds to the red retroverted stripe depicted in the $36 \mathrm{~mm}$ THA impingement model (Figure 3(d)).

\section{Contemporary Ceramic-on-Ceramic (1990-Present)}

Historically, hip impingement was perceived as a risk with ceramic liners, in some cases leading to rim chipping and fracture [18] [19] [20]. As a result, metal-backed cups with elevated metal rims were introduced by some manufacturers to protect ceramic liners. One such case with dramatic evidence of impingement presented to our clinic at Loma Linda University Medical Center (LLUMC). Beginning at 6 months, this patient's COC hip emitted distractingly loud noises while walking. Patient history revealed no dislocations or other mechanical problems. CT-scans showed her cup oriented with $55^{\circ}$ lateral opening and $30^{\circ}$ anteversion. Revision was planned when radiographs revealed her femoral-neck was notched [21]. Revision surgery at 3 years showed, 1) black staining of periarticular tissues, 2) femoral neck with twin notches, 3) black stained ceramic head, and 4) posteriorly notched Ti64 cup (Figure 4(a)). The neck notches could have been formed in two scenarios, i.e. combined liner and shell impingement creating a "double" notch (Figure $4(\mathrm{~b})$ ) or "twin" notches following $20^{\circ}$ of head subluxation (Figure 4(c)). Most likely, the posterior rim acted as fulcrum for the neck, enabling the head's anterior subluxation [21]. The revision surgeon trimmed the posterior Ti64 rim with a diamond burr and follow-up at 2-years showed hip noises had been eliminated. It was notable that our patient felt no discomfort or ROM limitation despite this 3-year experience with a squeaking THA. The learning experience was the degree of metallic damage created during this short follow-up.
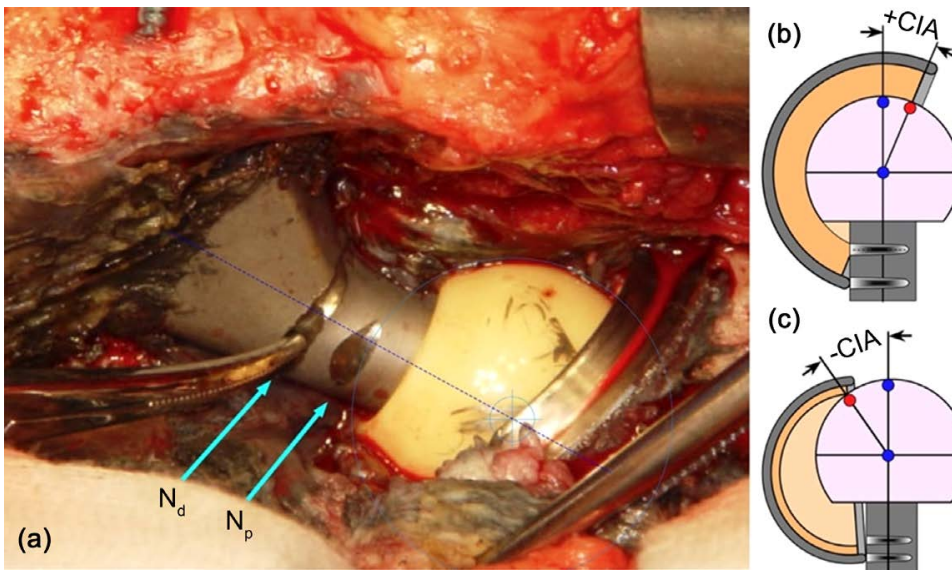

(c)

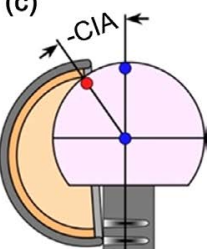

Figure 4. $28 \mathrm{~mm}$ COC revision showing, (a) black tissues, proximal/distal notches $\left(N_{p}\right.$, $N_{d}$ ), black stripes, and (b) "double notch" impingement concept, (c) "twin notch" subluxation concept [21]. 
Ball (2007) reported on 10 COC retrievals with black-stained surfaces [22]. The authors were concerned about intraoperative damage using a metal-backed cup with elevated metal rim (Encore, Austin TX). The authors noted that during head reduction, the elevated Ti64 rim transferred black stripes ( 0.5 - $1 \mathrm{~mm}$ wide) onto ceramic heads (4 surgeries). The other six cases with histories of dislocations showed black-stained ceramic that was related to damage of the metal-backed cups.

The Sydney orthopaedic group (SNHKS) [23] provided the first comprehensive review of stripe wear on contemporary COC designs. With up to 32 months follow-up, stripe damage on 11 heads was assessed by length, width, and depth of disruption, data recorded as 8 - $36 \mathrm{~mm}, 3-14 \mathrm{~mm}$, and 1 - $13 \mathrm{um}$, respectively. The stripe inclinations (Figure 2(c): SIA) averaged $20^{\circ}$ and all were termed "retroverted" (Figure 5(a)). This term described a stripe that traversed from anterolateral to posteromedial quadrant. This corresponded to the red stripe depicted in $36 \mathrm{~mm}$ COC model (see Figure 3(d)) and in LPUH "functional-sitting" video-2. SNHKS group [24]) also reported on relationships between hip squeaking and component positioning in 17 COC retrievals. Fifteen of the 17 retrievals used the non-cemented ABG II system (Trident cups, Osteonics/Stryker, NJ) with elevated metal rims (similar to Figure 4(a)). Hip noises began a few months to a few years post-surgery. Eight patients showed squeaking during hip-flexion activities, 4 patients consistently squeaked while walking, and another 5 cases squeaked after prolonged activities such as golfing. Esposito et al. with SNHKS group [17] provided stripe details in the largest COC retrieval study to date with follow-ups to 10 years (Figure 5(b), Figure 5(c): 54 cases). Stripe wear was demonstrable in $83 \%$ of retrieved heads. Heads revealed anterosuperior-E/L in 7 cases, posterior-E/L in 32 cases, and both types in 6 cases. Stripe inclination angles (SIA) peaked at $63^{\circ}-66^{\circ}$ (Figure 5(b), Figure 5(c)), which in our method would be CIA angles of $24^{\circ}-27^{\circ}$ (see Figure $2(\mathrm{c})$ ). It is noted that this is within the theoretical CIA-impingement range $\left(22^{\circ}-30^{\circ}\right)$ for 28 and $32 \mathrm{~mm}$ diameter heads.

(a)

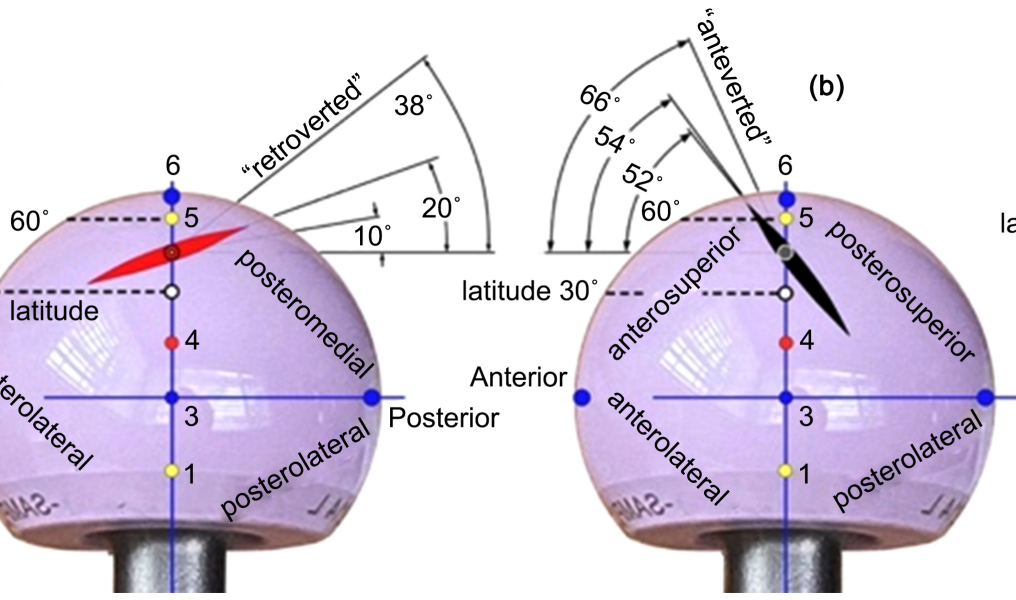

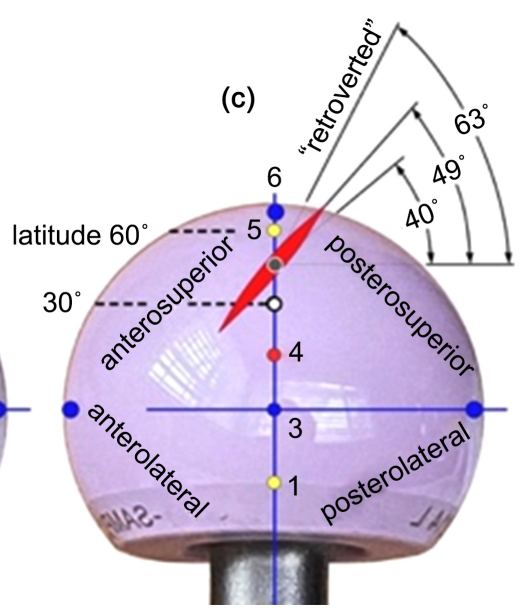

Figure 5. COC stripe inclinations (SIA) in SNHKS retrievals [17] [23]. 


\section{Ceramic-on-Ceramic Summary}

Despite frequent loosening problems in early COC designs, the consensus was that the rims of ceramic cups produced stripe wear on heads (head-E/L). Cups showed rim-E/L anterosuperiorly and posteroinferiorly and sometimes circumferentially (Figure 1). The large SNHKS study demonstrated stripe wear in $83 \%$ of cases, stripes formed in hip flexion being the most common. Overall, there was a consensus that damage commonly found in COC retrievals included head stripes, cup-rim wear, neck impingement, and metallic-stained surfaces [25]. Optimization continues in contemporary THA design but does not eliminate impingement risks. Metal transfer continues to be reported, an unequivocal sign of metallic impingement [26]-[35].

Our learning experience from the $36 \mathrm{~mm}$ COC model and LPUH videos was that stripe inclinations were related to femoral-neck widths (Figure 2, Figure 3). Large head:neck ratios resulted in greater ROM, producing steeper stripe inclinations at impingement. Steeper stripes were predicted following head subluxation, capable of crossing over the polar axis. Note that our $36 \mathrm{~mm}$ impingement model does not purport to represent anatomical functional positions. This model (Figure 3) makes no allowance for cup anteversion/lateral-inclination, femoral anteversion, or femoral-neck width. For this report, the LPUH videos offer the anatomical realism and comparisons of THA and RA designs in functional postures.

\section{Pioneering Metal-on-Metal (1965-1975)}

A variety of metal-on-metal (MOM) designs emerged during the 1960 era [36]. The pioneering McKee-Farrar THA (MKF) developed in England (1960-65) became widely used as a cemented design from 1965 onwards. The monolithic femoral component had a curved stem, large-diameter head and a short, wide neck (Figure 1(a)). Early results proved disappointing by today's standards with loosening rates of $50 \%$ and higher. It was noted that loose cups typically migrated in the superomedial direction $\left(0^{\circ}-30^{\circ}\right.$ from vertical axis), this corresponding to the typical inclination of the resultant hip force [37] [38] [39]. Nevertheless, the MKF retrievals had the significant benefit for retrieval studies in that the femoral head was not modular, thereby no ambiguity regarding head orientation in-vivo. Retrieval studies described both equatorial and polar wear patterns as well as peripheral wear stripes [40] [41] [42] [43] [44]. It was thought that "equatorial contact" denoted high frictional-torques able to promote cup loosening, i.e. "cup jamming". Impingement damage was also visible on femoral necks and periarticular tissues were frequently stained gray by CoCr debris.

We analyzed a long-term MKF retrieval to validate LLUMC methodology and for literature comparisons. The MWZ was carefully delineated taking care to differentiate wear patterns from iridescent band of gelatinous protein layers that frequently clustered along wear boundaries. Approximately $1.8 \mathrm{mg}$ of degraded protein could be removed from MOM heads by chemical-washing [45] [46] [47]. 
This particular MKF did not show any stripe wear. The typical wear-pattern (Figure 1(a): MWZ) was circular in shape and oriented such that the narrowest main-wear boundary was located at the superolateral head margin (Figure 6(a): dimension Z). It helped that the centroidal axis of the MWZ was centered adjacent to component midline and slightly superior to the polar axis (Figure 6(b)). Head MWZ was circular with its area representing 51\% hemi-wear ratio (MWA). The cup MWZ area was larger, corresponding to MWA ratio of 79\%. With cup positioned at $30^{\circ}$ inclination, the MWZ centroidal axis (C) corresponded to presumed line-of-action of the resultant hip-joint force (Figure 6(a): $15^{\circ}$ medial inclination). This reverse-engineering of head and cup MWZ appeared typical of MKF radiographic images [39].

\section{Contemporary Metal-on-Metal (2000-Present)}

Modular COC and MOM retrievals [1] [2] [10] represent additional complexities in mapping wear patterns. An antero-posterior THA x-ray serves here as an example (Figure 7(a)). The head and neck (left hip depicted) shows approximately $38^{\circ}$ inclination to the horizontal and the acetabular cup approximately $48^{\circ}$. For the purpose of discussion, it will be assumed that this is a reasonable approximation for "functional-standing" posture in LPUH videos. Anatomical definitions for medial/lateral and inferior/superior are as depicted. However, unless the revision surgeon marks each component during surgery, all anatomical landmarks are lost. Typically, the polar axis $(\mathrm{P})$ is the sole identifiable landmark in modular femoral heads (Figure 7(b), Figure 7(c)).

Retrieval studies at LLUMC necessitated a standard procedure for determining wear patterns on modular heads and cup-liners. Simulator studies provided us a foundation for retrieval analyses [12] [13] [16] [48]-[55]. Our first large-diameter MOM retrieval involved a patient troubled by multiple-dislocations. The hip

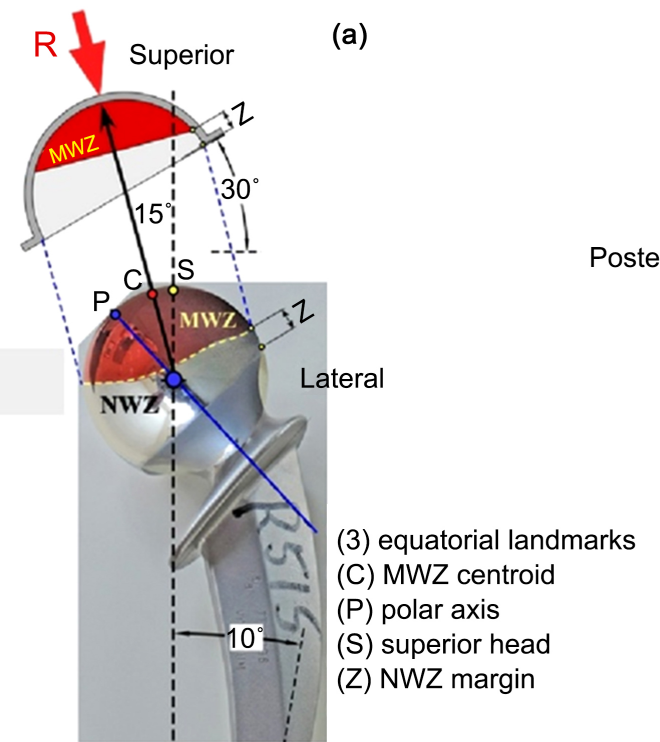

(b)

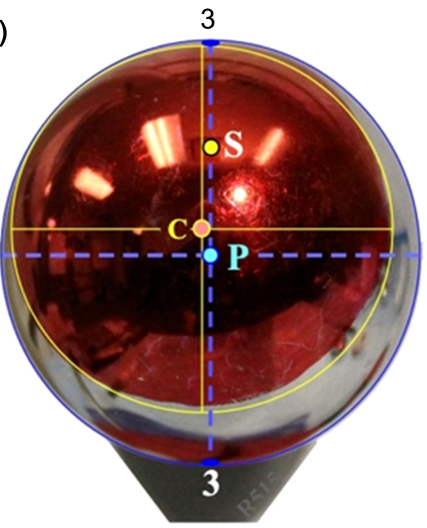

MWZ = $1046 \mathrm{~mm}^{2}$ head area $=2623 \mathrm{~mm}^{2}$ hemi-area $(\mathrm{MWA})=40 \%$

Figure 6. MKF wear pattern, (a) THA reverse engineering, (b) polar-axis view. 

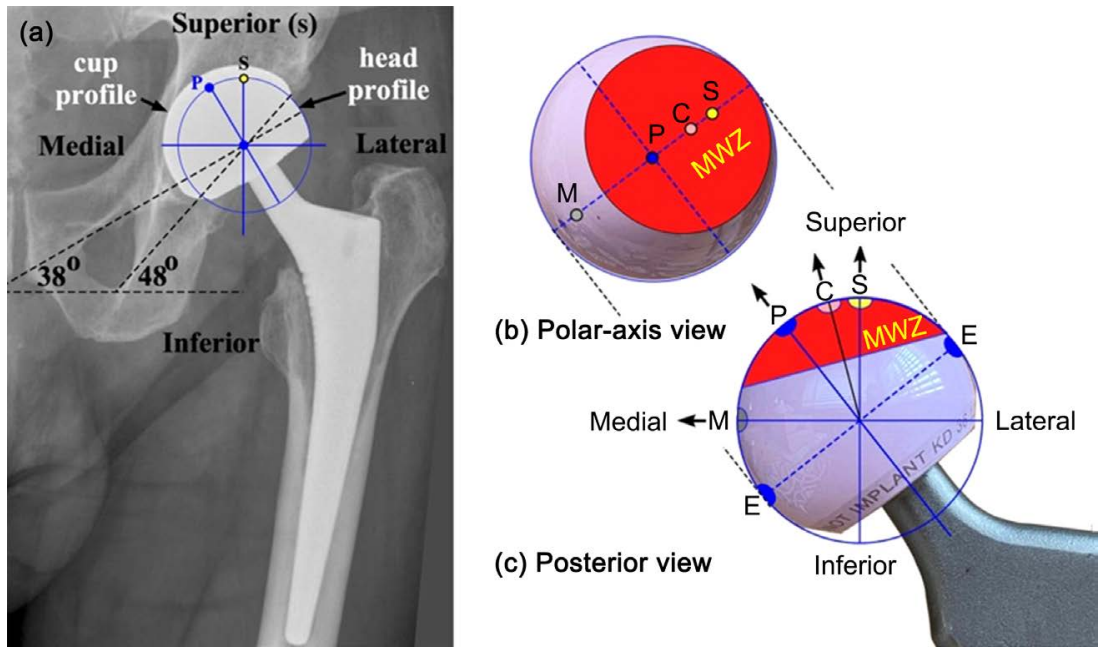

Figure 7. Anatomical landmarks in (a) radiograph of left hip, with 2 views of retrieval as (b) polar and (c) posterior.

dislocated 7 times over the two years leading to revision [56]. CT-imaging revealed an acetabular cup with steep inclination $\left(65^{\circ}\right)$ and considerable retroversion $\left(15^{\circ}\right)$. This case demonstrated main-wear zones, stripe-wear, and large areas of Ti64 contamination. MWZ patterns on head and cup were well polished with average roughness $\mathrm{Ra}<25 \mathrm{~nm}$. The differences between this case and our MKF retrieval raised the question, how much bearing surface does the patient habitually use, and how does that vary with THA diameter? Review of the literature and LLUMC data provided six hypotheses:

1) Head wear patterns (MWZ) are circular to mildly elliptical in polar region

2) Head MWA-ratios range up to $55 \%$

3) Narrowest MWZ margin indicates superolateral head position in-vivo

4) Centroidal-axis of head MWZ lies adjacent to stem centerline and superior to polar-axis

5) Inclination of MWZ centroidal axis corresponds to resultant hip-force (R) in-vivo

6) Polar head stripes represent edge-loading by the cup-rim

LLUMC received a contemporary THA design with still-fused $50 \mathrm{~mm}$ head. This provided the opportunity to validate MWZ methodology on large-diameter MOM. This female patient had a steeply-inclined cup [57]. Her painful left hip emitted creaking and crepitus sensations and was revised at 32 months. The narrow MWZ-margin was identified (Figure 8(a)) and photographed to show the superolateral wear pattern. The prosthesis was then rotated in $90^{\circ}$ increments to record three more views. Thus, the superior head margin $(\mathrm{Z})$ and inferior margin (M) appeared in two views each. The MWZ centroid was located adjacent to the stem midline and approximately midway between polar $(\mathrm{P})$ and superior (S) axes (Figure 8(a)). Reverse-engineering of MWZ onto patient radiographs illustrated the likely in-vivo position (Figure 8(b)). A satisfactory alignment of MWZ centroidal axis with $15^{\circ}$ line-of-action of (hypothetical) resultant hip-force (R) [37] [38] was taken as appropriate validation. 

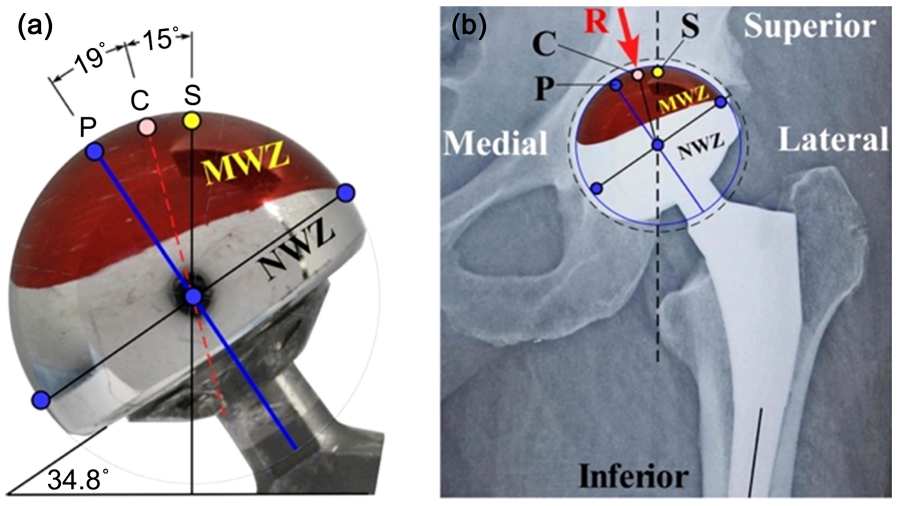

Figure 8. Polar wear pattern on $50 \mathrm{~mm}$ fused-head [57], (a) anteroposterior view, and (b) reverse engineering on patient's radiograph.

LLUMC analyzed $60 \mathrm{MOM}$ retrievals for patterns of normal and adverse wear [58]. Large-diameter THA were represented by three vendors (Biomet, Depuy, Smith and Nephew) while the MOM controls on loan from LPUH were $28 \mathrm{~mm}$ Metasul (Zimmer). Overall, head MWZ was noted to be a circular area with a slight elliptical tendency and MWZ areas increased with MOM diameter. Hemi-area ratios ranged $34 \%-77 \%$ with average MWA of 53\% (Figure 9). Cup MWZ areas were larger than heads and more varied (MWA $=65 \%)$. Inclinations for centroidal vectors ranged from $5^{\circ}$ to $30^{\circ}$ superiorly (average $16^{\circ}$ ). These data were supportive of individual case studies at LLUMC. Overall, our original six hypotheses appeared relevant and in summary provided the following scope;

1) Head MWZ is circular in shape and centered near the pole

2) MWZ covers approximately $40 \%-60 \%$ of head surface

3) MWZ centroidal axis confirms head position (functional-standing)

4) Cup MWZ covers approximately $65 \%$ of hemispherical area

5) Cup MWZ seldom circular, rarely contained within rim

6) Cup MWZ matched with head MWZ confirms functional-standing position.

\section{Adverse Wear with Metal-on-Metal THA and RA}

$\mathrm{CoCr}$ retrievals were studied visually under stereo-lens magnification for evidence of stripe wear but these were found difficult to photograph and analyze. Stripes had to be sketched by hand onto our MWZ-charts using colors to denote basal, equatorial, and polar sites. By definition, polar stripes occurred in the head's main wear zone (MWZ) and basal stripes in the non-wear zone (NWZ). Basal and polar stripes were found in all MOM retrievals [58]. Basal-polar stripe combinations appeared at simulated prosthetic impingements (Figure 10). Multiple stripe combinations were observed in some retrievals (Figure 10, Figure 11(b)) [59] [60]. In contrast to basal-polar combinations, equatorial stripes varied considerably, occasionally following the cup-rim profile for considerable lengths (Figure 11(a): $40 \mathrm{~mm}$ arrows) but more typically appearing as irregular short stripes (Figure 10, Figure 11(b)). 


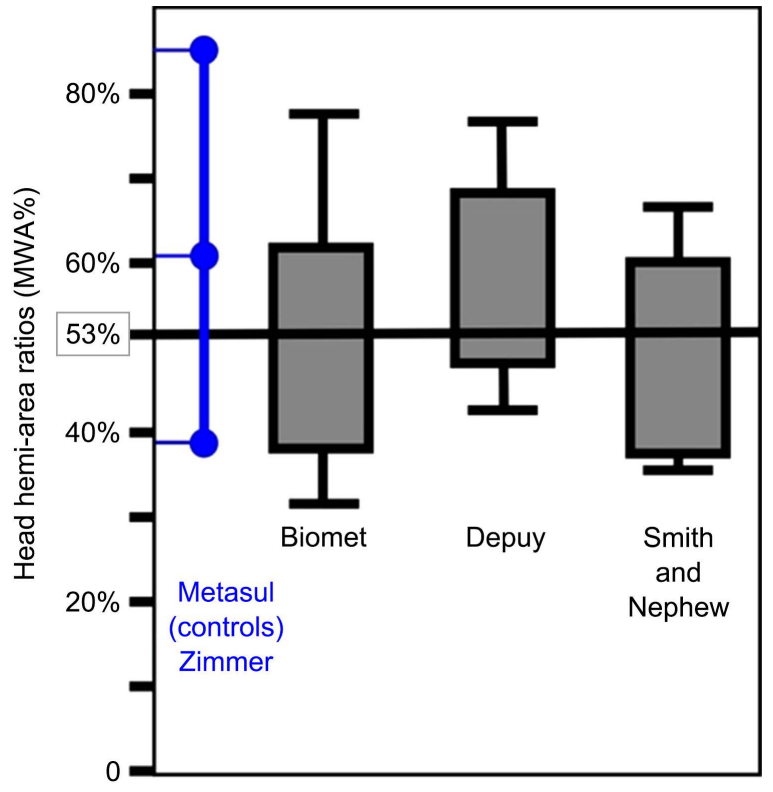

Figure 9. Polar wear-patterns on 60 modular heads [58].
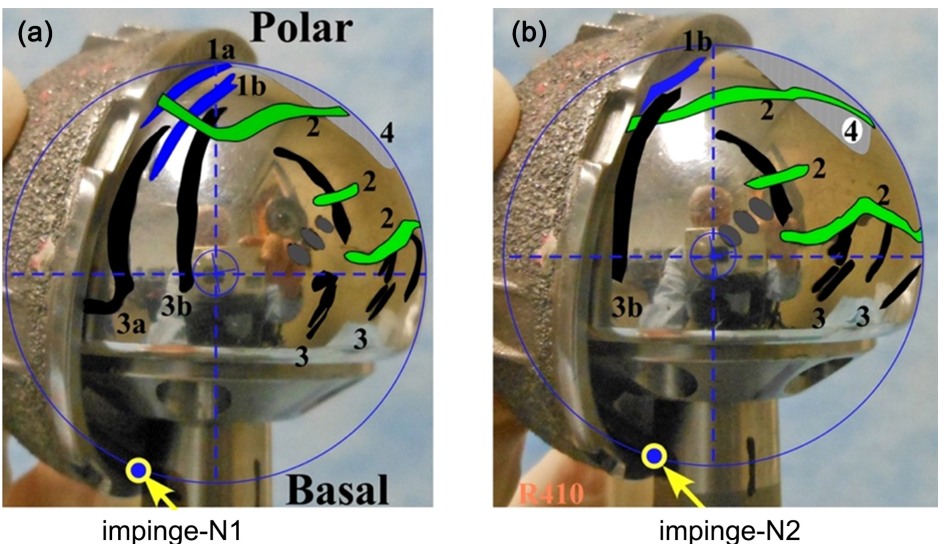

Figure 10. Stripes on $42 \mathrm{~mm}$ MOM, (a) cup-on-neck (N1), rim aligned on stripes polar 1a/basal 3a, and (b) cup on neck (N2), rim aligned on polar1b/basal3b, also showing protein contaminants (\#4) [58].

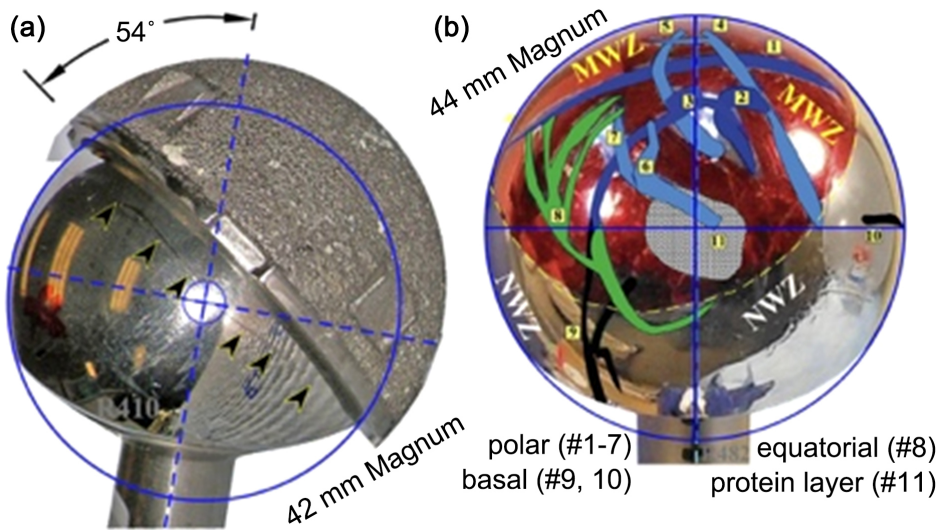

Figure 11. Magnum head retrievals (a) head subluxed to show $40 \mathrm{~mm}$ stripe (arrows) and (b) multiplicity of stripes in dislocator case [60]. 
The "twin" neck-notches observed in some THA retrievals (Figure 4(a)) represented a "subluxation" wear mechanism that does not appear to have been discussed in the literature (Figure $4(\mathrm{c})$ ). The $3 \mathrm{D}$-video LPUH models provide the opportunity to evaluate this "subluxation" hypothesis. Video-3 in functional-standing depicts the femoral head subluxing from the cup during the posterior-impingement maneuver. The appearance of a $2^{\text {nd }}$ black stripe at a steeper inclination depicts head-E/L during this maneuver. Video-4 in functional-sitting depicts head subluxation following the anterior impingement. The $2^{\text {nd }}$ red stripe formed at a steeper inclination brings it closer to the head's polar axis. Head stripes crossing within their polar circle (Figure 3(c), Figure 3(d)) were therefore witness to subluxation of the femoral head.

Approximately 15 years ago, Howie et al. [61] published a landmark study identifying $100 \mu \mathrm{m}$ wide scratches in $20 \mathrm{MKF}$ retrievals. LLUMC termed such scratches "microgrooves" [58] to differentiate them from prior descriptions of "fine CoCr scratches" (0.1 - $10 \mu \mathrm{m}$ quoted range) [62] [63] [64] [65]. LLUMC utilized white-light interferometry (WLI) and scanning electron microscopy (SEM) to characterize microgrooves. The "stripe" damage could be represented by a large microgroove or by arrays of parallel microgrooves particularly when Ti64 contamination was present. Microgrooves varied in width from 40 to 400 $\mu \mathrm{m}$ with $100 \mu \mathrm{m}$ being typical. Large pits and gouges were found in association with microgrooves, indicative of either impacting debris or sub-surface loss due to fracture [66]. Microgrooves were most conspicuous in the inferior head margins (NWZ). Basal microgrooves varied 3 - $20 \mu \mathrm{m}$ deep with jagged lips of equal height to valleys (Figure 12). The longitudinal striations in larger microgrooves along with shallow entry and exit termini indicated that these were created by metal particles plowing across $\mathrm{CoCr}$ surfaces, i.e. classic $3^{\text {rd }}$-body wear mechanism. Basal microgrooves were frequently found contaminated with Ti64 alloy in the non-wear zone. Long smears of Ti64 transfer varied $40-160 \mu \mathrm{m}$ in width and quite commonly presented as twin tracks up to $300 \mu \mathrm{m}$ wide or more (Figure 12(a)). These revealed Ti64 "islands" with 1 to $5 \mu \mathrm{m}$ peaks above the CoCr surface (Figure 12(c), Figure 12(d)). In contrast, polar microgrooves (MWZ) were not so well defined, sometimes resembling sawtooth patterns with $1-2 \mu \mathrm{m}$ depth (Figure 13). With average roughness index $200-300 \mathrm{~nm}$, these stripes were much rougher than adjacent polished MWZ surfaces (5 - $20 \mathrm{~nm}$ ).

Clearly RSA hips with large femoral necks will impinge more readily than THA [67]. The main difference would be that, in the absence of a prosthetic femoral-neck, there would be no risk of "prosthetic" impingement. This raised the question, would RSA femoral components show similar pits, microgrooves, and stripe wear as THA? We analyzed 12 each THA and RSA retrievals that had adequate clinical information and could be matched by vendor and diameter [68]. RA bearings revealed surface pitting, sometimes singly, sometimes grouped, and frequently in linear formations. The pits were typically $150-160 \mu \mathrm{m}$ wide, 5 - $15 \mu \mathrm{m}$ deep, frequently found adjacent to microgrooves, and present in both femoral and acetabular components. In other words, RSA wear damage appeared 

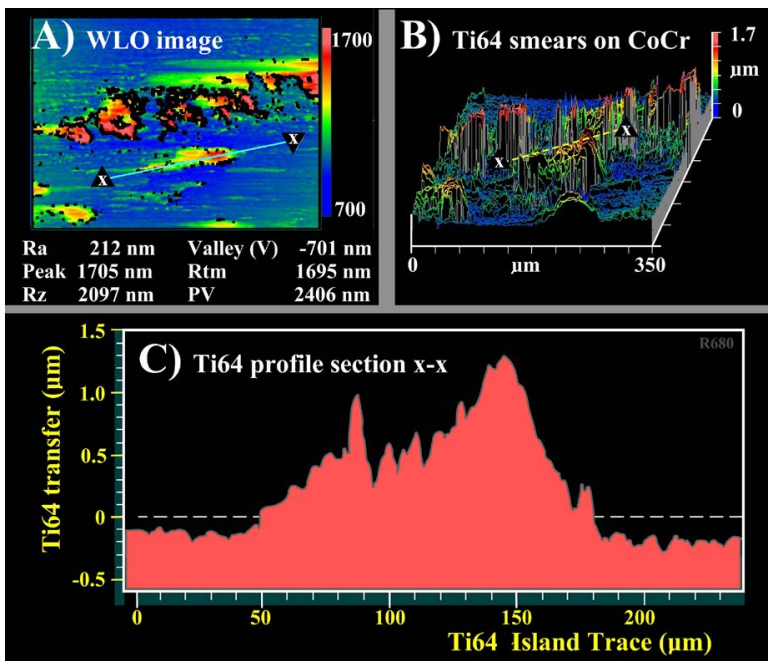

Figure 12. $36 \mathrm{~mm}$ CoCr head [58]. (a) Ti64-smear profile (x-x) in WLO imaging; (b) Oblique view of Ti64 islands on smeared CoCr surface; (c) Cross-sectional profile ( $\mathrm{x}-\mathrm{x})$ of Ti64 island.

(a) white-light interferometry

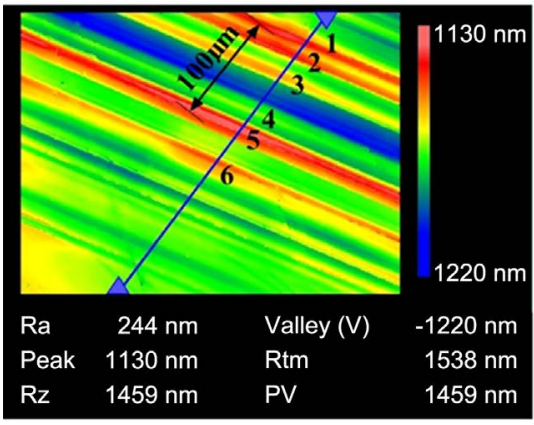

(b) Oblique profile "sawtooth"

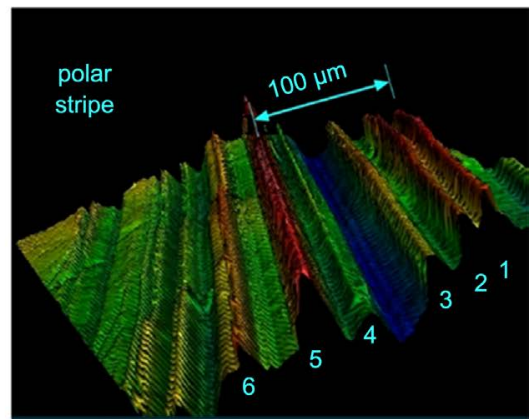

(c) "Sawtooth" stripe profile

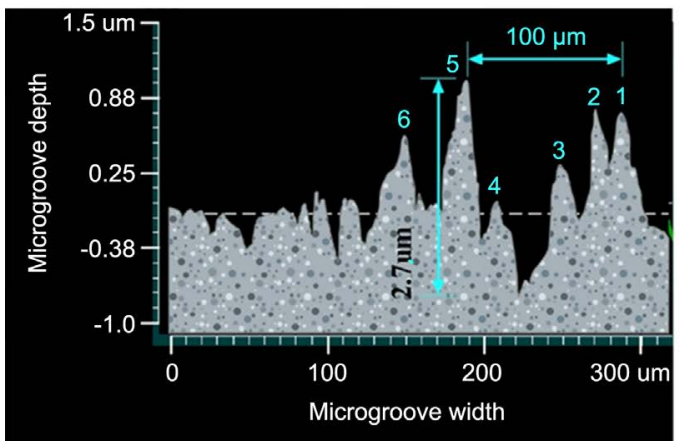

(d) Light microscpy

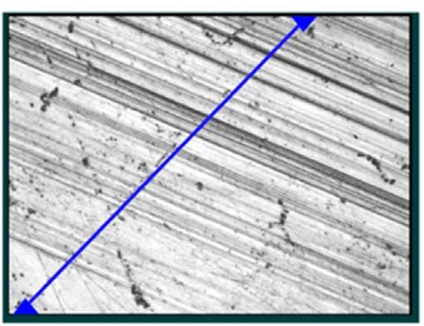

Figure 13. WLO-imaging polar microgrooves (36 $\mathrm{mm}$ head) with "sawtooth" rough surface.

similar to THA. WLI-imaging of THA liners (Figure 14(a), Figure 14(b)) and RA liners (Figure 14(c), Figure 14(d)) revealed similar features, notably longitudinal striations (1: $3^{\text {rd }}$-body wear), raised scratch lips (2: cold flow), surface distortion on flanks (3: cold flow) that were raised above the articular surface (4). Some microgrooves had conspicuous lipping on one side only (Figure 14(b)) and some both sides (Figure 14(d)). Aspect ratios (AR) varied anywhere from 

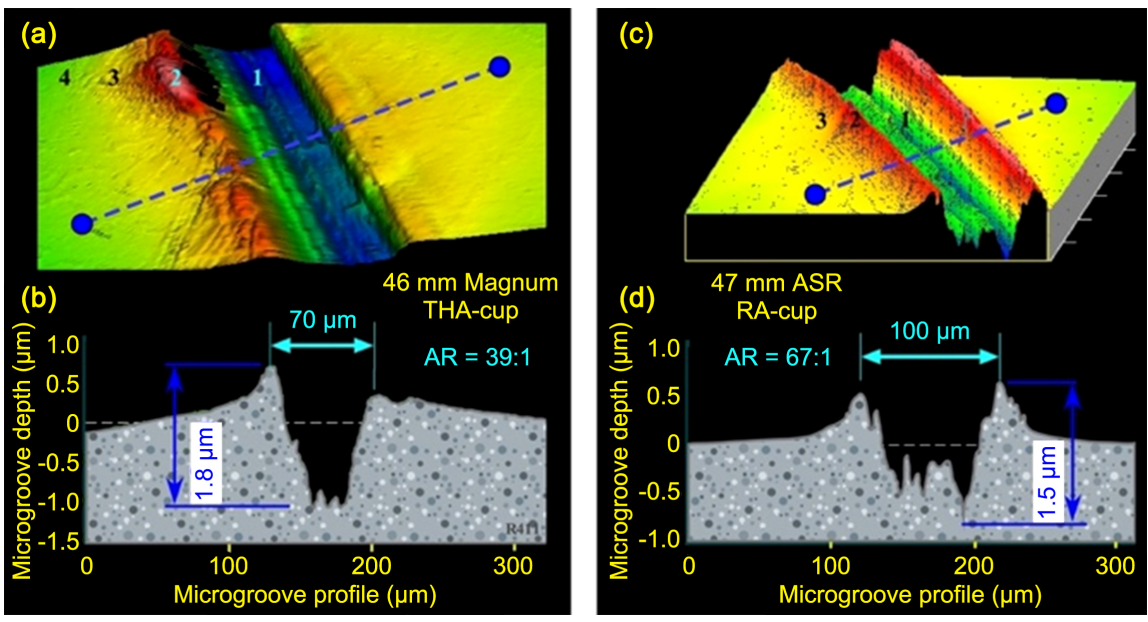

Figure 14. Microgrooves in CoCr liners [68]; (a) (b) THA (46 mm Magnum, Biomet) and (c) (d) 47 mm RA (ASR, Depuy).

30:1 to 70:1, indicating these were wide, shallow scratches. The large pits and scratches in RA could have been caused by, 1) metal debris released from bone-ingrowth surfaces, or 2) 2-body wear mechanisms (head-E/L, cup-E/L). Either way the conclusion was the same, $3^{\text {rd }}$-body wear in RA bearings was very similar to THA [68]. Comparing basal and polar stripe inclinations was particularly revealing. RA basal stripes averaged $29^{\circ}$ inclination (low head:neck ratio) to THA averaging $16^{\circ}$ (high head:neck ratio). However, polar stripes in RA and THA were virtually identical, averaging $14^{\circ}-17^{\circ}$ inclination. These data indicated that RA hips first impinged and then subluxed ( $12^{\circ}$ on average) to achieve same ROM as THA. As a result, RA and THA polar stripes appeared similarly inclined [67].

The video clips from La Pitié-Salpêtrière University Hospital (LPUH) depict resurfacing (RA) impingements in "functional-standing" and "functional-sitting" postures. In video-5, the femoral-head and neck represent a resurfacing arthroplasty (left hip). The $1^{\text {st }}$ segment depicts frontal and lateral views of cup on left and right sides of screen, respectively. With hip-extension, the large neck impinges on the posteroinferior cup rim (lateral view) at a more inferior site than with THA. Note the black stripe appearing on contra-rim site with shallow inclination i.e. less steep than THA. The $2^{\text {nd }}$ segment depicts posterior impingement from a perspective of inferior view of cup. Video-6 depicts the RA model in functional-sitting. The black head stripe formed in extension is retained for comparison. With hip-flexion, the neck impinges on the anterosuperior cup rim creating edge-loading on its anterior facet. Note the red stripe indicating cup profile at contra-rim site, this representing posteroinferior edge-loading of head and cup.

Video-7 depicts subluxation of the femoral head following posterior impingement in functional standing. The $2^{\text {nd }}$ black stripe formed with RA subluxation shows a steeper inclination, bringing it quite close to the polar axis. Video-8 depicts subluxation of the femoral head following anterior impingement in functional sitting. Video-8 starts showing two stripes from impingement (vid- 
eo-6) and the black stripe from subluxation in extension (video-7). The $2^{\text {nd }}$ red stripe formed with subluxation has a steeper inclination, bringing it quite close to the polar axis.

\section{Summary of Metal-on-Metal Wear Patterns}

The definition of functional wear zones (MWZ) in modular heads represented a critical first step in our analysis. The half-angle subtending the typical MWZ by definition was $60^{\circ}$ (MWA-ratio $\left.=50 \%\right)$. This was sketched on retrieval photographs to separate main-wear from non-wear regions (Figure 15). With cups mounted on surrogate femoral stems, details of polar (MWZ) and basal (NWZ) combinations were examined at prosthetic impingement sites. This simulation denoted four sites for potential edge-loading, i.e. neck-E/L(1), inferior cup-E/L(2), superior cup-E/l(3) and head-E/L(4), along with the ingress of Ti64 contamination in basal head region (8). Bearing surfaces on all MOM studied at LLUMC revealed large pits, microgrooves, stripe formations, and Ti64 transfer in many cases. Basal and polar stripes were observed on all MOM retrievals regardless of diameter or brand. CoCr heads featured the typical 100 um pits, microgrooves, side-wall striations, and Ti64 transfer that made us favor a $3^{\text {rd }}$-body wear mechanism. In contrast, McHugh et al. [69] anticipated plastic deformation on femoral heads that would denote forceful collisions by the cup rim. This was certainly possible in polar regions, some stripes revealing multiples of microgrooves, a sawtooth pattern that could have denoted a repetitive mechanical impingement (Figure 13). The counterpoint would be that the longitudinal striations in microgroove valleys indicated abrasion by travelling metal particles. In addition, similar pits and microgrooves formed inside CoCr liners could only have been due to $3^{\text {rd }}$ body wear. Our agreement may lie in the fact that metal particles could be released by a combination of abrasive-wear and fatigue-wear mechanisms.

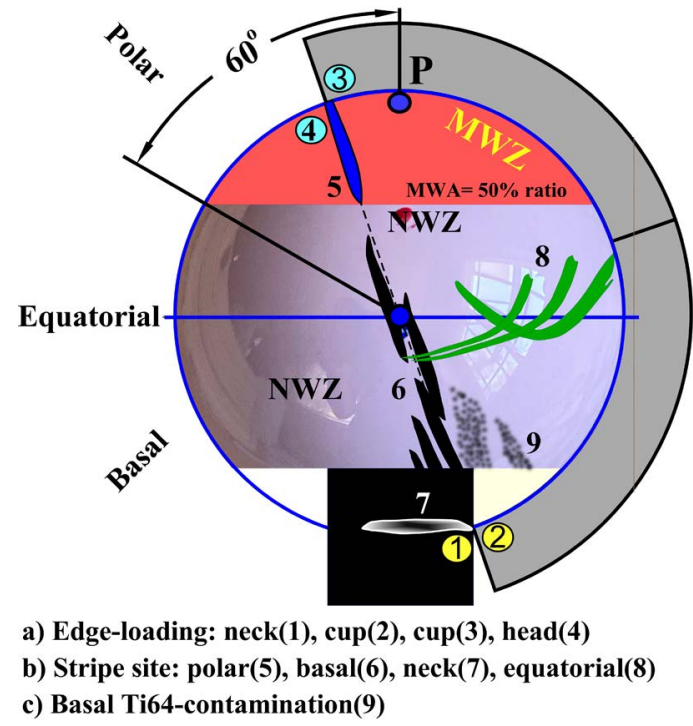

Figure 15. Mapping basal, equatorial, polar areas for impingement, stripes and Ti64 contamination. 
Hip impingement as a wear mechanism was inferred in the pioneering era of COC studies [1] [2] but apparently not considered in MOM analyses. This was likely a misconception given that $\mathrm{CoCr}$ was believed to offer beneficial "fluid-film" lubrication and "self-healing" wear mechanisms [70]-[78]. As originally described by Howie in MKF retrievals [61], the LLUMC retrievals confirmed large metal fragments had been circulating in both THA and RA retrievals. In THA cases, the metal particles could have originated from three sites (head-E/L, cup-E/L, neck-E/L), or by metal beads released from coated components. In RA cases, the metal particles could only have originated from a 2-body wear mechanism (head-E/L, neck-E/L) or by release of metal beads. Impingement differences between RA and THA wear mechanisms may be reflected in clinical outcomes, the RA designs generally proving superior to THA [79] [80] [81] [82].

\section{Impingement Evidence in Metal-on-Metal THA}

Basal-polar stripe combinations represented indirect evidence of prosthetic impingement (Figure 10, Figure 11, Figure 15). Femoral-neck proof was lacking because only 2 femoral stems were received in our study of 45 large-diameter MOM retrievals [58]. We note anecdotally that anodized Ti64 femoral necks frequently show loss of color, an indication of very mild wear by the cup rim (Figure 16(a), Figure 16(e)). While such rings represent unequivocal evidence of cup impingement, these were too shallow to be called notches so we termed these "circumferential blemishes". LPUH loaned LLUMC a set of ten Metasul THA (Zimmer, Warsaw, IN) complete with femoral stems. Circumferential damage was apparent as well-defined notches on 5 necks (Figures 16(b)-(d)) and as "blemishes" on 5 others [83]. One Metasul stem had three notches, one superior and two posterior. The latter were the "twin" notches similar to our COC retrieval case (Figure 4(a)). The Metasul model demonstrated cup-inclination CIA-angle of $32^{\circ}$ on the proximal notch (Figure 17(a)). The head needed to sublux a further $20^{\circ}$, enabling the cup rim to impinge more distally creating the $2^{\text {nd }}$ notch $\left(\mathrm{CIA}=-8^{\circ}\right)$ (Figure $17(\mathrm{~b})$ ). It was also apparent in these models that only the cup rim would remain in contact with the femoral neck and head (Figure 17(b)). We modelled this concept of cup "lift-off" (CLO) using our prior retrieval experience (Figure 4). For simplicity, the beveled cup rim was positioned at the cup's equator thereby providing a full $180^{\circ}$ bearing in the hypothetical model (28 mm diameter, $13.8 \mathrm{~mm}$ neck). We were interested in how quickly cup lift-off would disengage the bearing surfaces and eliminate MOM lubrication. The CLO algorithms (Figure 17(c), Figure 17(d)) revealed that even $1^{\circ}$ of subluxation in $28 \mathrm{~mm}$ and $44 \mathrm{~mm}$ MOM designs would result in gaps of $250 \mathrm{um}$ and $400 \mathrm{um}$, respectively. This gapping was approximately proportional to head geometry (Figure 17(c), Figure 17(d)). Therefore, the larger the MOM diameter, the larger the gap during subluxation. It is to be noted that even $1^{\circ}$ of subluxation would transfer all hip-joint force across the cup's narrow beveled rim in contact with the head. 


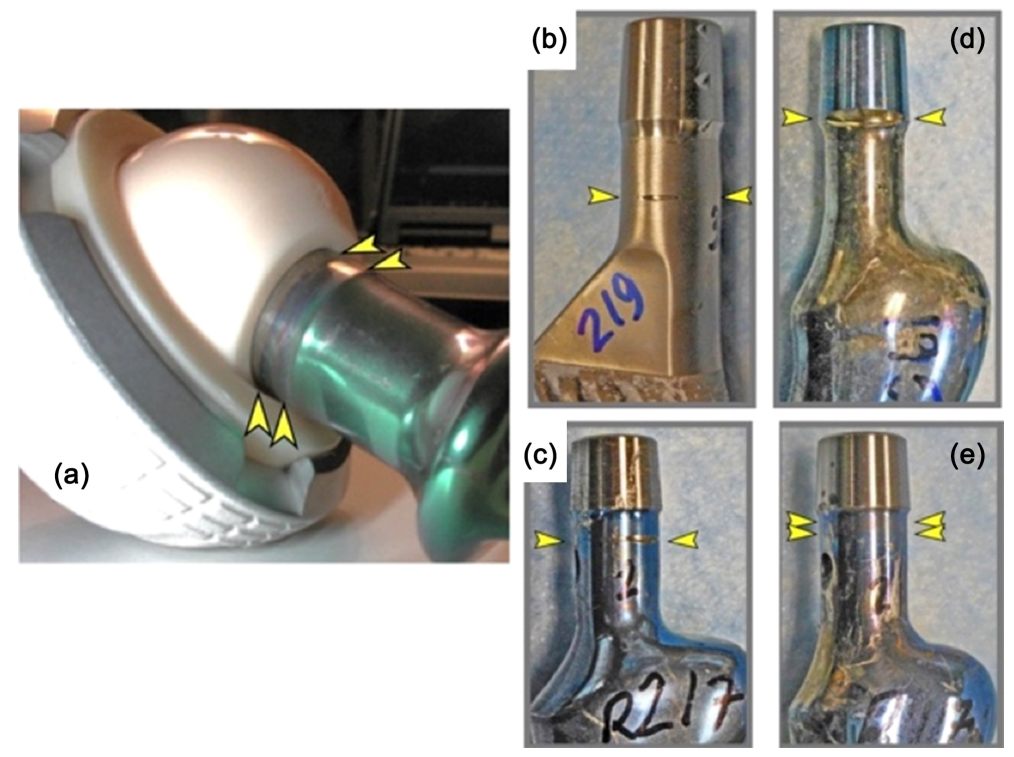

Figure 16. COC and MOM necks, (a) circumferential blemishes, anodized Ti64 neck (28 mm Ceraver: arrows), (b) CoCr notch, (c) Ti64 notch, (d) Ti64 trunnion notch, (e) Ti64 blemishes [83].
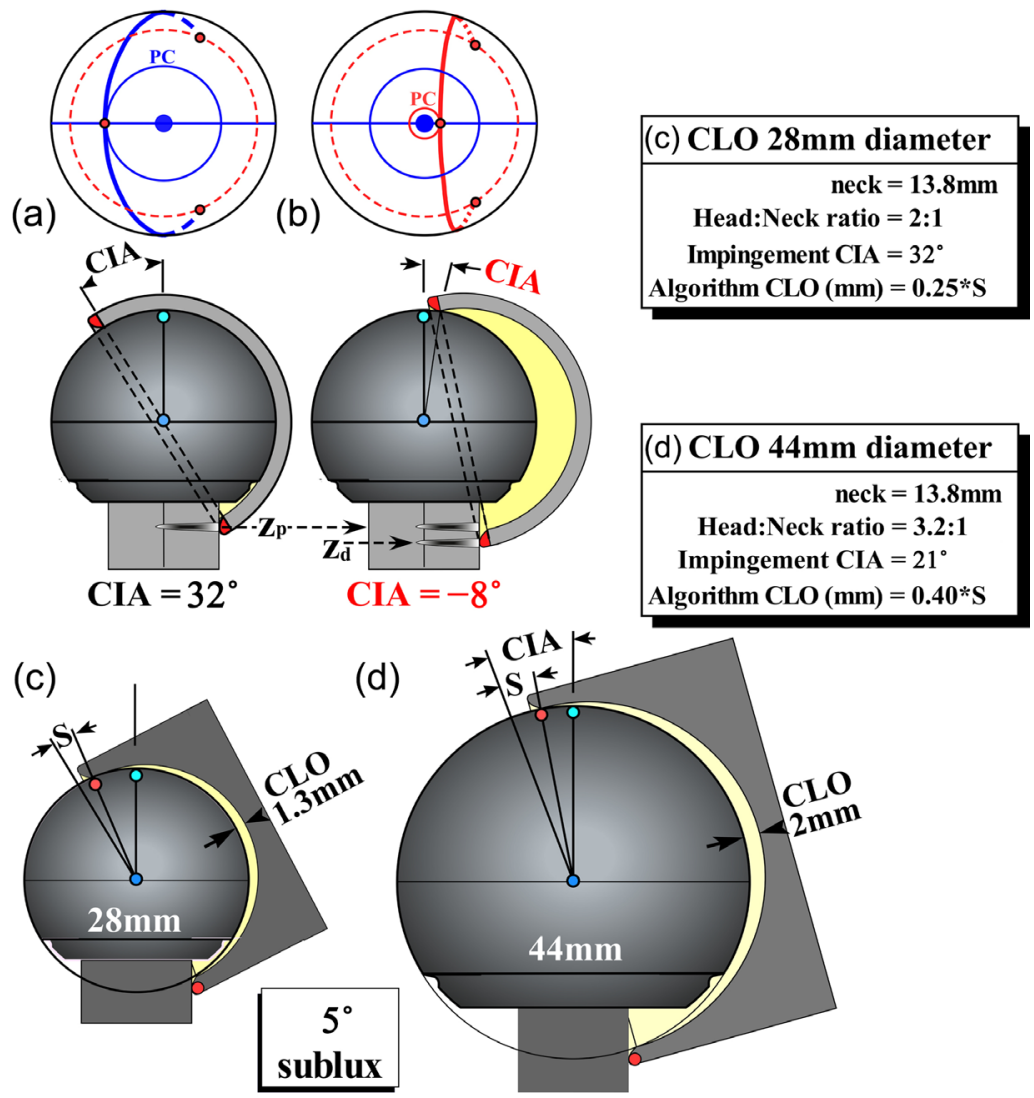

(d)

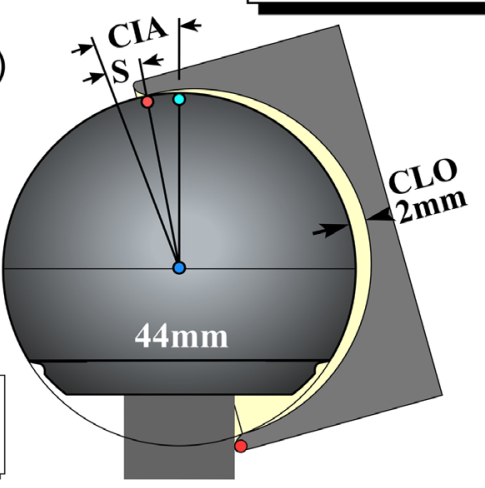

Figure 17. Modelling impingement and head subluxation with cup rim-contour positioned to replicate a hemispherical surface ( $28 \mathrm{~mm} 180^{\circ}$-cup, $13.8 \mathrm{~mm}$ neck), (a) at impingement CIA $32^{\circ}$, cup profile on head indicated above, (b) at $20^{\circ}$ subluxation cup profile crossed polar axis and CIA $-8^{\circ}$, (c) $28 \mathrm{~mm}$ cup with $5^{\circ}$ subluxation, and (d) $44 \mathrm{~mm}$ cup with $5^{\circ}$ subluxation. 
Individual THA cases referred to LLUMC also demonstrated dramatic evidence of neck notching. A bilateral THA patient was referred to LLUMC with persistent pain in the MOM hip. The female patient complained her right hip would freeze while walking and popped when rising from a chair. Imaging revealed a femoral stem anteverted $43^{\circ}$ and cup anteverted $40^{\circ}$. Revision at 3.5 years showed periarticular tissues stained black [84]. The revised $\mathrm{CoCr}$ head showed Ti64 smears $5 \mu \mathrm{m}$ thick. The femoral neck had two well-defined notches typical of prosthetic impingement (Figure 18(a)). The notches were not the "twins" that denoted head subluxation (Figure 4(a), Figure 4(c)). In this case, the contours of the Ultamet liner and Pinnacle shell exactly matched the double-notched Ti64 neck. This retrieval became our model for predicting a wear spectrum in neck-notches. Interestingly, except for the shallow rim indent, the Ultima cup showed little damage.

It was notable that polished surfaces in Ti64 notches (Figure 16(d), Figure 18(a)) resembled "precision machining". There was seldom a suggestion of plastic deformation denoting metal components colliding forcefully as anticipated by McHugh et al. [69]. Notch wear is characterized here (Figure 18(b)) by a 1 mm-thick "slice" containing twelve $1 \mathrm{~mm}$ cubes. Given that the two notches also spanned $6.25 \mathrm{~mm}$ neck width, it would be reasonable to assume notch volume could be represented by several such slices, perhaps approaching 21-cube volume, i.e. $21 \mathrm{~mm}^{3}$ total. This represented a $6 \mathrm{~mm}^{3} /$ year wear rate in the Ti64 notch. It is impossible to predict numbers and size-distributions of metal particles that would be released during presumed "millions" of wear cycles. At one end of the particle-size spectrum, $6 \mathrm{~mm}^{3}$ would represent annual release of 5700 particles of 126 um-size as quoted in MOP retrievals [85], approximating a daily release of 16 Ti64 particles. At the other end of the spectrum, if we hypothesize

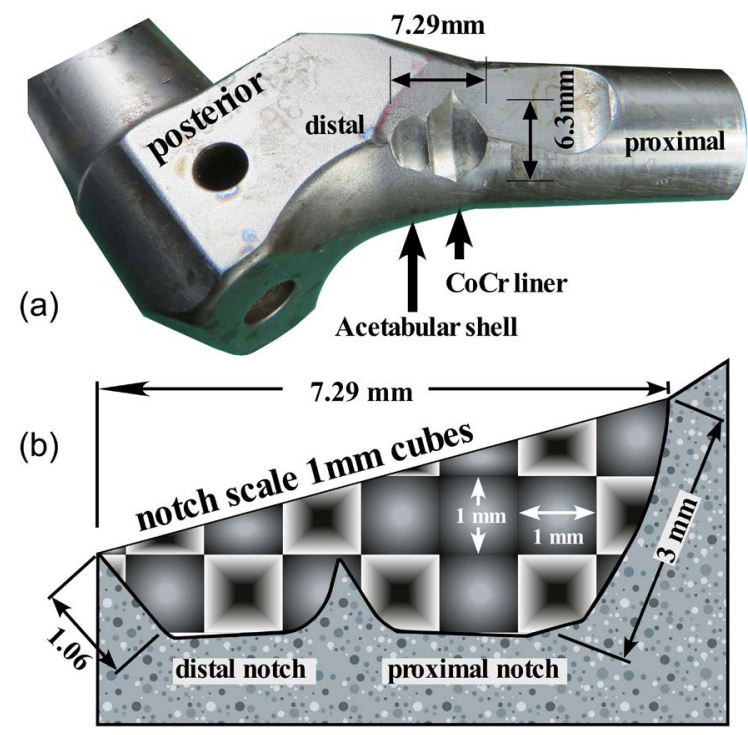

Figure 18. Retrieved Ti64 SROM (right hip) [84], (a) neck notched superoposteriorly, and (b) sectional wear model for "double" notch. 


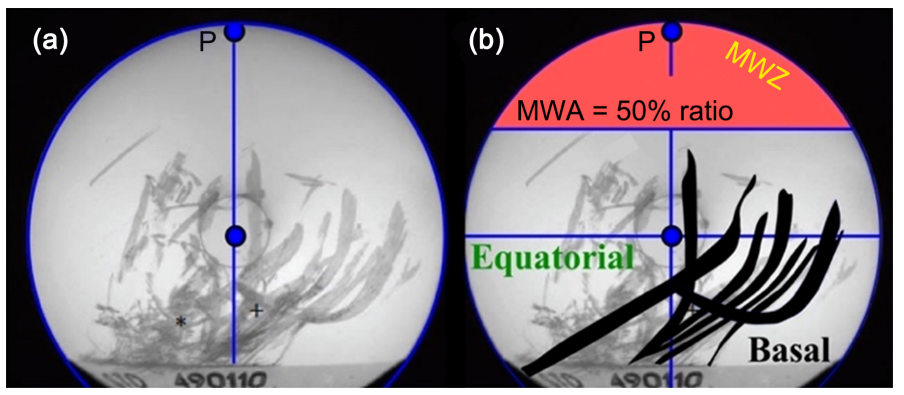

Figure 19. Retrieved CoCr head related to MOP dislocation [105] showing (a) Ti64 transfer, and (b) superimposed wear template.

that all metal particles were crushed between MOM surfaces [86] to the equivalent nanometer size found in tissues [87], this notch model represented approximately 22 -trillion Ti64 particles annually deposited in the joint. Some may consider this case an "extreme" example of THA impingement? Nevertheless, it does illustrate a potential wear spectrum that has been not explored in contemporary MOM literature [79] [88]-[93].

\section{Summary of MOM Wear Patterns in THA and RA}

Our learning experience from the RA and THA retrievals was that evidence of pitting, microgrooves and stripe-wear was essentially similar. In RA cases, the CoCr particles could have come from 1) loose beads, 2) cup-E/L and head-E/L mechanisms, or 3) both. Given the weight of retrieval evidence, our focus remains on edge-loading being most likely [1] [40] [61] [94] [95].

Theories of "boundary" and "fluid-film" lubrication have been advanced to predict optimal wear mechanisms for MOM, particularly in designing head: cup pairings with small clearances. However, it is to be noted that this concept is based on theoretical treatments predicting fluid-film thickness of the order 30 $\mathrm{nm}$ [58] [61] [63] [78] [85]. Retrieval evidence shows hip debris can be 3 to 4 orders of magnitude greater than that. This was not considered in lubrication theory. Additionally, THA and RA retrieval evidence shows that hip subluxation may actually be anticipated. Even $1^{\circ}$ of hip subluxation would create severe edge-loading when a rigid cup off-loads approximately 250 - 400 um from the head (Figure 17). The actual incidence cannot be predicted but impingement/subluxation may happen regularly, for example while doing yoga, tennis, dancing, golfing, riding horses, power walking, etc.

The COC consensus was that head "stripes" were created by ceramic cup-E/L. [1] [2] [12] [13] [16] [17] [23] [96]. This was apparently not anticipated in MOM studies. LLUMC data appears to be the first recognition of the MOM impingement concept advanced in the Australian study (Table 1). A key sentence in this work stated, "Scanning electron microscopy demonstrated deep wear tracks oriented in a common direction (Figure 2, [61])". This paper requires our study because their key micrograph showed a 100 um-wide scratch crossing a CoCr femoral-head (Figure 5, [61]). We coined the term "microgroove" to dif- 
ferentiate such large scratches that to our knowledge were not discussed either before or after this Australian report [58]. The importance of the microgroove was the insight that this provided to abrasive wear mechanisms in MOM bearings. Note that neck-E/L is typically referred to as a "notch" and head-E/L as a "stripe". From our point of view, "stripes" and "notches" represent a 2-body wear mechanism that edge-loading by a rigid cup produced over millions of wear cycles.

We therefore proceed with the following observations and hypotheses,

1) Head basal-polar stripe combinations indicate impingement

2) Head-E/L and cup-E/L release CoCr particles in MOM bearings

3) Cup edge-loading is the counterpoint to head-E/L

4) Pits and microgrooves in THA and RA indicate similar 3rd-body wear

5) Head stripes crossing near polar axis indicate head subluxation

6) Circumferential neck "blemishes" indicate "mild" edge loading

7) Neck notches indicate severe edge-loading by cups

8) Twin neck notches indicate head subluxation

9) Notch-wear model in Ti64 case predicts $6 \mathrm{~mm}^{3} /$ year wear rate

10) Simulator models revealed metal particles crushed to sub-micron size within seconds

\section{Impingement Evidence in Metal-on-Plastic Retrievals}

Our wear hypothesis stated above is that MOM and COC bearings readily crush large metal particles in vivo [86]. Therefore, metal-on-plastic (MOP) retrievals should have retained some evidence showing such metal particles. This we shall demonstrate using an assemblage of MOP reports (Table 1).

MOP designs in 1970 and 1980 era included femoral-head materials such as ceramic, CoCr, stainless steel, and titanium alloy [97] [98] [99] [100]. Following the cemented PE-cups [101], there was a move to non-cemented cups that used metal backings. For brevity, the term CEM-cups will refer to PE liners used with cement (no metal shell) and NC-cups to those using PE-liners with metal-backings. Ti64 femoral heads were also popular in the 1980 era, initially used successfully with CEM-cups. However, when replaced by NC-cups, THA revision rates increased resulting in the Ti64 femoral-heads being abandoned [97] [102]. In a MOP retrieval study of CoCr heads, $3^{\text {rd }}$-body wear was visible in $89 \%$ of MOP retrievals [103]. SEM imaging described $0.1-5 \mu \mathrm{m}$ scratches with jagged lips as typical. The authors concluded that this was $3^{\text {rd }}$-body wear by metal particles and was more frequent in cases with NC-cups (Table 1).

MOP impingement denoted by deformed PE-liner rims has an incidence approaching $75 \%$ of retrievals [85] [104]. In Ohio State University (MOSU) study sampling of 194 retrievals, $93 \%$ of the particles embedded in the polyethylene were found to be metallic (Table 1). MOP retrievals representing impingement and dislocation cases have also shown Ti64 contamination. One described a case with Ti64 layers up to $4 \mu \mathrm{m}$ thick on the CoCr head [35]. Wear analyses from MOP cases revised at MOSU documented large areas of Ti64 contamination (Figure 19(a)). 
Table 1. Assemblage of information regarding COC, MOM and MOP.

\begin{tabular}{|c|c|c|c|c|}
\hline ID & Study & Year & Type & Details of impingement damage \\
\hline 1 & Walker [40] [110] & 1971,74 & MOM & McKee wear patterns (equatorial), neck-E/L, cup-E/L, gray-stained tissue \\
\hline 2 & Dorlot [1] [2] & 1989,91 & $\mathrm{COC}$ & Wear stripes, head \& cup E/L, gray-stained ceramic \\
\hline 3 & Jasty [103] & 1994 & MOP & CoCr wear damage more common with NC-cups \\
\hline 4 & McKellop [111] & 1996 & MOM & McKee wear patterns (non-equatorial), neck-E/L \\
\hline 5 & Iida $[112]$ & 1999 & MOM & $28 \mathrm{~mm}$ Metasul notched neck, neck-E/L, \\
\hline 6 & Nevelos [10] & 1999 & $\mathrm{COC}$ & Stripes, head and cup E/L, gray-stained ceramic \\
\hline 7 & Oparaugo [106] & 2001 & MOP & CEM-cup outcomes superior to NC-cups \\
\hline 8 & Eickmann $[21]$ & 2003 & $\mathrm{COC}$ & Squeaking, elevated cup rims, notched neck \& cup rim, black-stained tissues \\
\hline 9 & $\begin{array}{c}\text { TMU [12] [13] [16] } \\
\text { [54] [113] }\end{array}$ & 2003-09 & $\mathrm{COC}$ & Polar MWZ, stripes, cup-E/L, gray-stained linear tracks, \\
\hline 10 & Walter [23] & 2004 & $\mathrm{COC}$ & Stripes (retroverted), head-E/L \\
\hline 11 & Howie $[61]$ & 2005 & MOM & McKee-Farrar, microgrooves, neck-E/L \\
\hline 12 & Walter [24] & 2007 & $\mathrm{COC}$ & Squeaking noises using cups with elevated metal rims \\
\hline 13 & Bal [22] & 2007 & $\mathrm{COC}$ & Squeaking noises, elevated cup rims, black-stained ceramic, Ti64 contamination \\
\hline 14 & Kligman [104] & 2007 & MOP & Polyethylene rim impingement in $75 \%$ of retrievals \\
\hline 15 & Lundberg [85] & 2007 & MOP & Rim impingement in $68 \%$ retrievals, metal debris embedded in liners, 126 um avg. size \\
\hline 16 & Bengs [67] & 2008 & MOM & RA impingement more likely than THA \\
\hline 17 & Bowsher [56] & 2008 & MOM & Multiple dislocator, polar wear-pattern, stripes, Ti64 contamination \\
\hline 18 & Patten [35] & 2010 & MOP & Dislocator case, Ti64 transfer 1 - 4 um thick, particle $10 \times 40$ um, PE delamination \\
\hline 19 & Kubo $[114]$ & 2011 & MOM & Metasul impingement, head and liner stripes, Ti metal ions, \\
\hline 20 & Esposito [17] & 2012 & $\mathrm{COC}$ & stripes anteverted and retroverted, head-E/L \\
\hline 21 & McPherson [59] & 2012 & MOM & Multiple-dislocator case, clicking noises, multiplicity of stripes \\
\hline 22 & Pelt $[60]$ & 2013 & MOM & Basal-polar stripes, head \& cup-E/L, histopathology \\
\hline 23 & McHugh [69] & 2013 & MOM & Stripe wear modelled as regions of plastic deformation \\
\hline 24 & Wong [65] & 2013 & MOP & MWZ (MWA= 45\% avg.), no pitting or microgrooves, CoCr roughness $\mathrm{Ra}=11 \mathrm{~nm}$ \\
\hline 25 & Nguyen [115] & 2013 & MOM & Large "Donga" pits with linear pattern of "skipping" pits common in NWZ \\
\hline 26 & Clarke [58] & 2013 & MOM & Polar MWZ $(\mathrm{MWA}=50 \%)$ basal-polar stripes, head \& cup-E/L, metal transfer \\
\hline 27 & Clarke $[83]$ & 2014 & MOM & $28 \mathrm{~mm}$ Metasul, circumferential blemishes and notching, $\mathrm{CoCr}$ and Ti64 necks \\
\hline 28 & Halim $[86]$ & 2014 & MOM & MOM simulator study crushed $\mathrm{CoCr}$ and Ti64 particles in 10-second test \\
\hline 29 & Halim [116] & 2015 & MOM & MOM simulator, wear with metal debris turned lubricants black over 5-million cycle test \\
\hline 30 & Donaldson $[84]$ & 2015 & MOM & $28 \mathrm{~mm}$ Pinnacle cup with double-notched SROM femoral neck \\
\hline 31 & Tikekar [105] & 2015 & MOP & 5 dislocator cases, Ti64 transfer average roughness $\mathrm{Ra}=0.3 \mathrm{um}$; peaks $\mathrm{Rz}=10-36 \mathrm{um}$ \\
\hline 32 & Elsissy [68] & 2018 & MOM & THA and RA, pits, microgrooves, stripes \\
\hline 33 & Munemoto [43] & 2018 & MOM & Histopathology in MKF retrievals over 2 to 41 years \\
\hline 34 & Karachalios $[80]$ & 2018 & MOP & NJR revision data, NC-cups $=\mathrm{x} 2$ greater than CEM-PE \\
\hline
\end{tabular}


Details of metal transfer can be compared with other studies (Figure 15) by superimposing MWZ-template showing likely wear zones (Figure 19(b)). In the depicted MOSU example (Figure 20), the metal transfer did not resemble basal stripes seen in MOM (Figures 10-12). Nevertheless, linear smears and Ti64-coated basal microgrooves have also been identified in MOM retrievals. The roughness on Ti64 "islands" ranged 1 - 5 um high (Figure 12(d)). MOP data suggested that during daily activities, circulating Ti64 particles were compressed between the PE-liners and CoCr heads (Figure 4 in MOSU report) [105] and thus (a) coated CoCr heads and (b) likely embedded in PE surfaces [85]. The resulting average surface roughness index (Ra) in the MOSU study was 300 nanometers with peaks (Rz) ranging to a high of 36 microns. For comparison, MOP cases $(\mathrm{N}=6)$ revised at LLUMC with more than 10-year follow-up demonstrated $\mathrm{CoCr}$ average surface roughness in normal low range of $8-13 \mathrm{~nm}$ [65]. The effect of Ti64 roughness coating CoCr heads is unknown with respect to MOP wear.

Interest in prosthetic impingement at LLUMC led to a study ranking MOP literature by head diameter, CEM versus NC-cups, and PE wear-rates (Table 1). The conclusions offered [106] suggested that 1) best clinical outcomes were with $22 \mathrm{~mm} / 28 \mathrm{~mm}$ heads in CEM-cups, while NC-cups showed poorer outcomes for all categories $(22-32 \mathrm{~mm})$. A literature review from the University General Hospital of Larissa [80] offered similar conclusions (circa 2018), primarily taken from the National Joint Registry (England, Wales, and N. Ireland). The authors presented conclusions as follows, 1) compared with NC and hybrid-fixation, CEM-THA had the lowest revision-rates over all time periods, and 2) revision rate with NC-THA was approximately double that of CEM-THA. Given the MOP impingement record (Table 1), the most likely cause would be NC-cups impinging on metal femoral-necks with releasing metal particles, thereby Ti64 being the greatest risk. It is to be noted that THA with multiple bearings also share impingement risks (Figure 20).

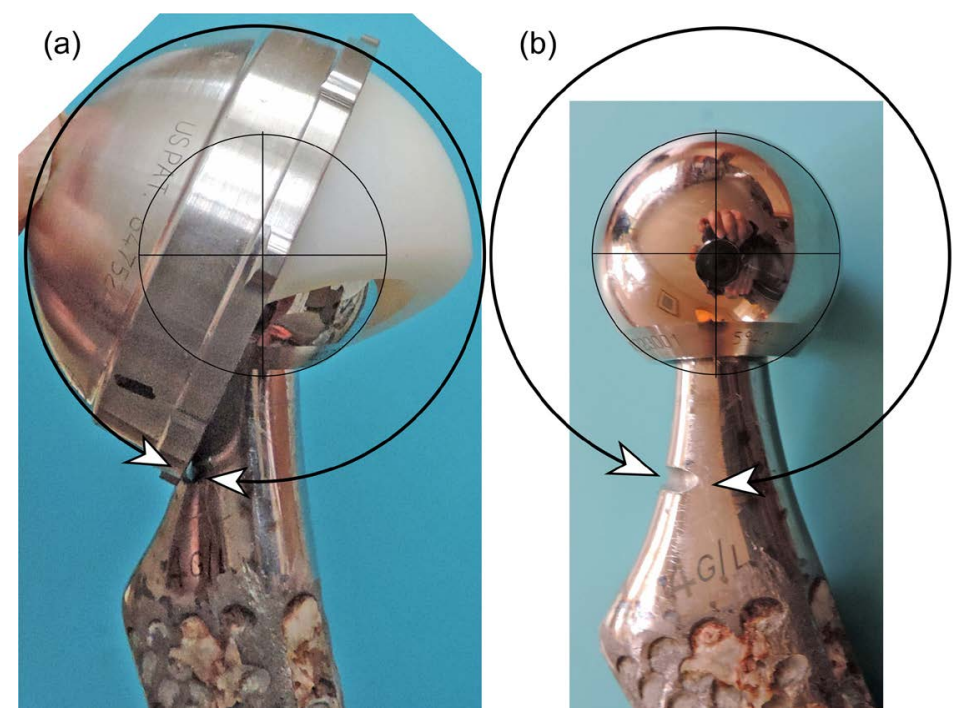

Figure 20. Notched neck in multiple-bearing MOP (young female, revised after 1 year). 


\section{Assemblage of Impingement Evidence (COC MOM, MOP)}

The initial focus of MOM studies (1965-1975) was on polar versus equatorial wear-patterns. Peripheral stripe-wear and neck impingement also received some mention. COC clinical studies had their debut circa 1970-1973 in France and Germany. The consensus in these early studies was that "stripe" wear on ceramic heads represented edge-loading by cup rims. However, these data frequently represented loose components and this somewhat clouded interpretation. Gray-stained alumina surfaces demonstrated that metal particles had been circulating. Nevertheless, studies of contemporary THA designs later confirmed that stripe wear represented a typical COC wear mechanism.

In hindsight, two landmark McKee-Farrar (MKF) studies predicted the future for 2nd generation MOM results. An early MKF report described metallosis and pseudotumors in seven retrievals [107] and this was confirmed recently in long-term studies [43]. A report on $24 \mathrm{MKF}$ retrievals attributed $3^{\text {rd }}$-body $\mathrm{CoCr}$ wear to large CoCr particles being released at impingement [61] (Table 2). This result was also confirmed recently [58]. Key wear patterns represented polar head wear combined with basal-polar head stripes and pertinent evidence of single, "twin", and "double" notches on femoral necks. Without these key observations, surface pitting, scratching and Ti64 transfer could simply have been written off as 1) surgical damage, 2) dislocation damage, and/or 3) loose beads. We now add that head "stripes" and femoral neck "notches" represent precisely-sited wear mechanisms that could only be replicated by "prosthetic" impingement. The 3D anatomical simulations of impingement in LPUH videos brought awareness of stripe formations and the cup "lift-off" mechanism in functional-standing and sitting postures. This new CLO-concept implies that as the femoral head subluxes from the cup, there will be two dramatic changes, 1) sudden loss of lubrication, and 2) cup rim transmits total hip-joint force onto a narrow strip of head surface. Even one degree of head subluxation from a rigid cup enables 200 microns surface gapping.

The well-polished surfaces of femoral notches represented a wear mechanism functioning over "millions" of load cycles. Estimated metal loss due to neck-notching (Ti64 neck, 3.5-year revision) presented a wear-rate approaching $6 \mathrm{~mm}^{3} /$ year. Such an annual dose of Ti64 would represent 5700 particles of 126 um-size, a daily release of only 16 micron-size particles. The wear spectrum of neck-notching is unknown but this represents a clinically significant wear mechanism (Table 2) that has not been discussed in MOM literature (2-body wear).The counterpoint to femoral-neck notching was the formation of stripe wear on femoral heads. Descriptions of abrasive wear in hard CoCr alloy surfaces frequently ascribe such damage to release of surface carbides. As side by side comparisons indicate here, the scale of surface carbides (Figure 21(a): circled < $5 \mu \mathrm{m})$ is dwarfed by the typical microgroove of width $100 \mu \mathrm{m}$. The jagged lips and longitudinal striations illustrate the power in such $3^{\text {rd }}$ body wear by metal particles (Figure 21(b)). It can be appreciated that the metal particles traversing this surface had to be at least 100 - $200 \mu \mathrm{m}$ wide. 
Table 2. Release of metal particles (particularly Ti64) implicated in MOP outcomes.

\begin{tabular}{|c|c|c|c|}
\hline Date & Study & Parameter & Details \\
\hline 1981 & McKellop [117] & Pin-on-flat wear tests (MOP) & Adverse wear: PMMA debris on Ti64 \\
\hline 1988 & Agins [102] & Ti64 femoral heads (MOP) & Abandoned \\
\hline 1991 & Jasty [103] & CoCr roughened by metal debris (MOP) & Rougher with NC-cups \\
\hline 1999 & Iida [112] & Neck notch, metallosis (MOM) & Ti64 femoral neck \\
\hline 2003 & Eickmann [21] & Impinged Ti64 femoral neck (COC) & “Twin" neck notches, elevated Ti64 rim \\
\hline 2005 & Howie $[61]$ & McKee-Farrar retrievals & Impingement CoCr debris, 100 um scratches \\
\hline 2005 & Kim [27] & "Severe smears" on ceramic heads (COP) & PE-wear increased, metal smeared on ceramic \\
\hline 2007 & $\mathrm{Bal}[22]$ & Black Ti64 transfer (COC) & Ti64 femoral necks, elevated cup rims \\
\hline 2007 & Kligman [104] & Impinged polyethylene cups (MOP) & $75 \%$ of cup retrievals \\
\hline 2010 & Lee $[31]$ & COC neck notches, black metal transfer & "Twin" neck notches in Figure 2(a) \\
\hline 2013 & Clarke [83] & Impinged neck with "twin" notches (MOM) & Ti64 notches $\gg \mathrm{CoCr}$ \\
\hline 2013 & Clarke [58] & Impingement in $60 \mathrm{MOM}$ retrievals & Impingement, $\mathrm{CoCr}$ debris, microgrooves \\
\hline 2014 & Halim [86] & CoCr and Ti64 debris, MOM-simulator & Metal particles crushed in 10 -second test \\
\hline 2015 & Halim [116] & $3^{\text {rd }}$ body wear, MOM-simulator & Higher wear with Ti64 particles, black lubricants \\
\hline 2015 & Donaldson [84] & MOM “double-notch" in Ti64 neck & Ti64 neck-notch model (wear $6 \mathrm{~mm}^{3} /$ year) \\
\hline 2015 & Tikekar [105] & CoCr heads, Ti64 transfer (MOP) & Ti64 roughness $1-36 \mu \mathrm{m}$ on CoCr heads \\
\hline 2018 & Elsissy [68] & 3rd-body wear similar in RA and THA & CoCr debris (hip subluxation) \\
\hline 2018 & Karachalios [80] & MOP outcomes, UK Joint Registry & NC-cup revisions $=2 \mathrm{x}$ CEM-cups \\
\hline
\end{tabular}

The obvious circuit-breaker in our foundational impingement hypothesis was that prior revision and simulator studies described $\mathrm{CoCr}$ debris as minute, approaching 30 - 80 nanometers [63] [87]. There are three pieces of evidence that can explain this enigma. Firstly, most THA patients remain completely unaware of hip impingement and subluxation. This has been termed "repetitive sub-clinical subluxation" (RSS) [59]. We also found quite remarkable that considerable implant damage could materialize with quite short-term follow-ups (Figure 4, Figure 18, Figure 19). The second confirmation was found in MOP retrieval studies (Table 2) showing 1) debris embedded in PE liners was mostly metallic of average size $126 \mu \mathrm{m}$ size [85], and 2) Ti64 transfer onto CoCr heads could be $1-36 \mu \mathrm{m}$ thick [35] [105]. The $3^{\text {rd }}$ piece of evidence was provided by LLUMC simulator studies crushing large $\mathrm{CoCr}$ and Ti64 particles in 10-second MOM tests [86]. As follow-up, our second hypothesis introduces the wear mechanism of cup lift-off (Figure 17: CLO). Just $1^{\circ}$ of lift-off will create 250 to $400 \mu \mathrm{m}$ surface gapping. Not only does this void all lubrication but it also will trigger adverse stripe wear, i.e. total hip-force is now transferred into the segment of cup-rim in contact with the head. 


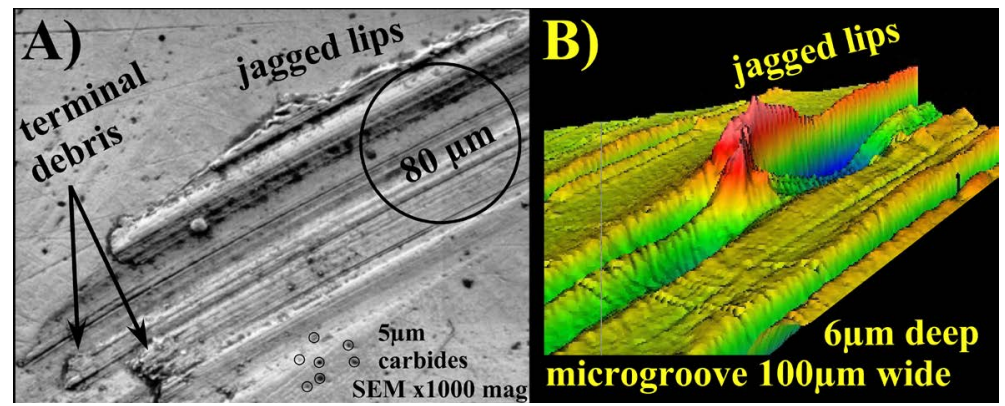

Figure 21. $3^{\text {rd }}$-body wear in CoCr head (43 mm ASR, Depuy, Warsaw IN) showing (a) SEM image comparing scale of a $80-100 \mu \mathrm{m}$ microgroove to the $5 \mu \mathrm{m}$ surface carbides (circled), and (b) WLO imaging of CoCr scratch details.

In conclusion, the consensus in COC studies was that stripe-wear damage on heads was produced by a cup edge-loading mechanism (cup-E/L). Metal particles were released as a result of impingement and as a result COC retrievals frequently showed black-stained surfaces. Regardless, alumina bearings are extremely resistant to $3^{\text {rd }}$-body abrasion. In contrast, MOM bearings proved very reactive to ingress of metal particles and now probably are relegated to use only by expert surgeons [79] [80] [81] [108] [109]. The MOP and COP THA remain the most forgiving designs in terms of impingement, i.e. no stripe wear and compliance in polyethylene liners likely negates concerns of cup "lift-off". Nevertheless, metal-backed polyethylene cups still risk "prosthetic" impingement (Figure 20). It is therefore relevant that MOP Registry data indicates outcomes with NC-cups were inferior to CEM-cups. It is notable that MOP retrievals demonstrated that 1) metal particles roughen CoCr heads, 2) metal particles embedded in PE liners average size 126 um and 3) Ti64 transfer onto CoCr heads ranged up to $36 \mathrm{um}$ thick. It is also noted that the wear performance of Ti64 surfaces and Ti64 debris has always been negative (Table 2). Ti64 necks typically show the most notch damage. Nevertheless, market preference remains with NC-cup designs, in particular with Ti64 metal-backings used to support bone ingrowth. These data indicate a need for MOP and COP wear studies regarding 1) prosthetic impingement, 2) lift-off by rigid cups (CLO), 3) Ti64-transfer onto CoCr femoral heads, and 4) $3^{\text {rd }}$-body wear by large metal particles (126 um).

\section{Acknowledgements}

MOM retrieval and simulator studies at LLUMC were funded by FDA contracts,

1) Analysis and validation of wear and corrosion performance of metal on metal hip explants (FDA1090360).

2) Development and Validation of Improved Premarket Testing methods (simulator studies) for Metal-on-Metal (MOM) Hip Replacements (FDA1090372).

We also acknowledge financial support to our retrieval studies from

1) Arthroplasty for Arthritis Charity (a4ach.org)

2) Dept of Orthopaedics, La Pitié-Salpêtrière University Hospital, Paris 


\section{3) DARF Retrieval Center (LLUMC)}

The authors are grateful to Professors A. Imakiire and K. Yamamoto, Dept. Orthopaedics, Tokyo Medical University (TMU) whose interests in tribology supported the contributions and publications of TMU Research Fellows at LLUMC. The expertise of V. Good, M. Burgett, T. Halim and R. Moran as managers of the DARF Center and Howard and Irene Peterson Tribology Laboratory at LLUMC were indispensable in our research programs. We are also very grateful for the support of retrieval surgeons, including HC. Amstutz (Los Angeles), M. Boehler, Vienna (Austria), P. Burton (Los Angeles), A. Gustafson (Loma Linda), A. John (Cardiff), K. Keggi MD (Connecticut), E. McPherson (Los Angeles), H. Oonishi (Osaka), C. Peters (Salt Lake City), L. Sedel (Paris), A. Stark (Stockholm), and N. Sugano (Osaka).

\section{Conflicts of Interest}

The authors declare no conflicts of interest regarding the publication of this paper.

\section{References}

[1] Dorlot, J.M. (1992) Long-Term Effects of Alumina Components in Total Hip Prostheses. Clinical Orthopaedics and Related Research, 282, 47-52. https://doi.org/10.1097/00003086-199209000-00006

[2] Dorlot, J.M., Christel, P. and Meunier, A. (1989) Wear Analysis of Retrieved Alumina Heads and Sockets of Hip Prostheses. Journal of Biomedical Materials Research, 23, 299-310. https://doi.org/10.1002/jbm.820231405

[3] Plitz, W. and Griss, P. (1981) Clinical, Histo-Morphological, and Material Related Observations on Removed Alumina-Ceramic Hip Joint Components. In: Weinstein A., Gibbons, D., Brown, S. and Ruff, W., Eds., Implant Retrieval: Material and Biological Analysis, National Bureau of Standards, Gaithersburg, 131-156.

[4] Griss, P., Silber, R., Merkle, B., Haehner, K., Heimke, G. and Krempien, B. (1976) Biomechanically Induced Tissue Reactions after $\mathrm{Al}_{2} \mathrm{O}_{3}$-Ceramic Hip Joint Replacement. Experimental and Early Clinical Results. Journal of Biomedical Materials Research, 10, 519-28. https://doi.org/10.1002/jbm.820100407

[5] McKee, G.K. (1970) 10 Development of Total Prosthetic Replacement of the Hip. Clinical Orthopaedics and Related Research, 72, 85-103. https://doi.org/10.1097/00003086-197009000-00011

[6] Griss, P. (1984) Four- to Eight-Year Postoperative Results of the Partially Uncemented Lindenhof-Type Ceramic Hip Endoprosthesis. In: Morscher, E., Ed., The Cementless Fixation of Hip Endoprostheses, Springer-Verlag, Berlin, 220-224. https://doi.org/10.1007/978-3-642-69006-8_36

[7] Griss, P., Heimke, G. and von Andrian-Werburg, H.F. (1975) The Alumina Oxide Ceramic-Metal Composite Endoprosthesis. A New Hip Endoprosthesis for Partially Cement Free Implantation. Archiv für orthopädische und Unfall-Chirurgie, 81, 259-266. https://doi.org/10.1007/BF00416952

[8] Mittelmeier, H. and Harms, J. (1979) Treatment of Post-Traumatic Hip Joint Disease by Total Replacement with a Ceramic Endoprosthesis. Unfallheilkunde, 82, 67-75. 
[9] Boutin, P. (1972) Total Arthroplasty of the Hip by Sintered Alumina Prostheses. Orthopaedics and Traumatology Surgery Research, 100, 15-21.

[10] Nevelos, J.E., Ingham, E., Doyle, C., Fisher, J. and Nevelos, A.B. (1999) Analysis of Retrieved Alumina Ceramic Components from Mittelmeier Total Hip Prostheses. Biomaterials, 20, 1833-1840. https://doi.org/10.1016/S0142-9612(99)00081-2

[11] Mittelmeier, H. (1984) Cementless Revisions of Failed Total Hip Replacement: Ceramic Autophor Prosthesis. Hip, 1, 312-321.

[12] Shishido, T., Clarke, I.C., Williams, P., Boehler, M., Asano, T., Shoji, H., Masaoka, T., Yamamoto, K. and Imakiire, A. (2003) Clinical and Simulator Wear Study of Alumina Ceramic THR to 17 Years and Beyond. Journal of Biomedical Materials Research Part B: Applied Biomaterials, 67B, 638-647. https://doi.org/10.1002/jbm.b.10048

[13] Manaka, M., et al. (2004) Stripe Wear Rates in Alumina THR-Comparison of Microseparation Simulator Study with Retrieved Implants. Journal of Biomedical Materials Research Part B: Applied Biomaterials, 69B, 149-157.

https://doi.org/10.1002/jbm.b.20033

[14] Manaka, M., Clarke, I.C., Gustafson, A. and Imakiire, A. (2003) Impingement in Ceramic Hip Patient a Retrieval and Wear-Scar Analysis of Femoral Head. In: Ben-Nissan, B., Sher, D. and Walsh W., Eds., Key Engineering Materials, Vol. 240-242, Trans Tech Publications Ltd., Zurich-Uetikon, 847-848. https://doi.org/10.4028/www.scientific.net/KEM.240-242.847

[15] Yamamoto, K., et al. (2003) Wear Mode and Wear Mechanism of Retrieved Acetabular Cups. International Orthopaedics, 27, 286-290.

https://doi.org/10.1007/s00264-003-0477-2

[16] Tateiwa, T., Clarke, I.C., Pezzotti, G., Sedel, L., Kumakura, T., Shishido, T. and Yamamoto, K. (2007) Surface Micro-Analyses of Long-Term Worn Retrieved "Osteal $^{\mathrm{TM} "}$ Alumina Ceramic Total Hip Replacement. Journal of Biomedical Materials Research Part B: Applied Biomaterials, 83B, 562-570. https://doi.org/10.1002/jbm.b.30829

[17] Esposito, C.I., Walter, W.L., Roques, A., Tuke, M.A., Zicat, B.A., Walsh, W.R. and Walter, W.K. (2012) Wear in Alumina-on-Alumina Ceramic Bearings. A Retrieval Analysis of Edge Loading. The Journal of Bone and Joint Surgery. British Volume, 94, 901-907. https://doi.org/10.1302/0301-620X.94B7.29115

[18] Clarke, I.C., Pezzotti, G. and Sugano, N. (2013) Materials in Hip Surgery: Mechanical Properties That Influence the Design and Performance of Ceramic Hip Bearings. In: Berry, D. and Lieberman, J., Eds., Surgery of the Hip, Elsevier, Amsterdam, 102-118.

[19] Clarke, I.C. (1992) Role of Ceramic Implants. Design and Clinical Success with Total Hip Prosthetic Ceramic-to-Ceramic Bearings. Clinical Orthopaedics and Related Research, 282, 19-30. https://doi.org/10.1097/00003086-199209000-00004

[20] Clarke, I.C., et al. (1988) Biomechanical Stability and Design. Wear. Annals of the New York Academy of Sciences, 523, 292-296.

https://doi.org/10.1111/j.1749-6632.1988.tb38524.x

[21] Eickmann, T.H., Clarke, I.C. and Gustafson, A. (2003) Squeaking in a Ceramic on Ceramic Total Hip. In: Zippel, H. and Dietrich, M., Eds., Bioceramics in Joint Arthroplasty, Steinkopff Verlag, Darmstadt, 187-192. https://doi.org/10.1007/978-3-642-85763-8_29

[22] Bal, B.S., Rahaman, M.N., Aleto, T., Scott Miller, F., Traina, F. and Toni, A. (2007) The Significance of Metal Staining on Alumina Femoral Heads in Total Hip Arth- 
roplasty. Journal of Arthroplasty, 22, 14-19. https://doi.org/10.1016/j.arth.2006.02.155

[23] Walter, W.L., Insley, G.M., Walter, W.K. and Tuke, M.A. (2004) Edge Loading in Third Generation Alumina Ceramic-on-Ceramic Bearings: Stripe Wear. Journal of Arthroplasty, 19, 402-413. https://doi.org/10.1016/j.arth.2003.09.018

[24] Walter, W.L., O’Toole, G.C., Walter, W.K., Ellis, A. and Zicat, B.A. (2007) Squeaking in Ceramic-on-Ceramic Hips: The Importance of Acetabular Component Orientation. Journal of Arthroplasty, 22, 496-503. https://doi.org/10.1016/j.arth.2006.06.018

[25] Brandt, J.-M., Gascoyne, T., Vecherya, A., Turgeon, T. and Bohm, E. (2018) Surface Damage Characterization on Thirty-Five Retrieved Contemporary Ceramic-on-Ceramic Total Hip Replacements. Orthopaedic Proceedings, 95B, Supp-1.

[26] Yoo, J.J., Kim, H.J. and Kim, Y.M. (2004) Damage of an Alumina-on-Alumina Bearing Surface from a Difficult Reduction of a Total Hip Arthroplasty. A Report of Three Cases. Journal of Bone and Joint Surgery, 86, 376-378. https://doi.org/10.2106/00004623-200402000-00025

[27] Kim, Y.H., Ritchie, A. and Hardaker, C. (2005) Surface Roughness of Ceramic Femoral Heads after In Vivo Transfer of Metal: Correlation to Polyethylene Wear. Journal of Bone and Joint Surgery, 87, 577-582. https://doi.org/10.2106/JBJS.D.01790

[28] Müller, F.A., Hagymási, M., Greil, P., Zeiler, G. and Schuh, A. (2006) Transfer of Metallic Debris after Dislocation of Ceramic Femoral Heads in Hip Prostheses. Archives of Orthopaedic and Trauma Surgery, 126, 174-180. https://doi.org/10.1007/s00402-006-0109-6

[29] Schuh, A., Mittelmeier, W., Zeiler, G., Behrend, D., Kircher, J. and Bader, R.(2006) Severe Damage of the Femoral Head after Dislocation and Difficult Reduction Maneuvers after Total Hip Arthroplasty. Archives of Orthopaedic and Trauma Surgery, 126, 134-137. https://doi.org/10.1007/s00402-005-0093-2

[30] Murali, R., Fiona Bonar, S., Kirsh, G., Walter, W.K. and Walter, W.L. (2008) Osteolysis in Third-Generation Alumina Ceramic-on-Ceramic Hip Bearings with Severe Impingement and Titanium Metallosis. Journal of Arthroplasty, 23, 1240.E13-1240.E19. https://doi.org/10.1016/j.arth.2007.10.020

[31] Kim, Y.H., Choi, Y. and Kim, J.S. (2010) Cementless Total Hip Arthroplasty with Ceramic-on-Ceramic Bearings in Patients Younger Than 45 Years with Femoral Head Necrosis. International Orthopaedics, 34, 1123-1127. https://doi.org/10.1007/s00264-009-0878-y

[32] Medel, F.J., Shah, P. and Kurtz, S.M. (2009) Retrieval Analysis of Contemporary Alternative Femoral Head Materials: Oxinium and Biolox Delta. Transactions of 55 th Annual Meeting of the Orthopaedic Research Society, Las Vegas, 22-25 February $2009,2300$.

[33] Eberhardt, A.W., Travis McKee, R., Cuckler, J.M., Peterson, D.W., Beck, P.R. and Lemons, J.E. (2009) Surface Roughness of $\mathrm{CoCr}$ and $\mathrm{ZrO}_{2}$ Femoral Heads with Metal Transfer: A Retrieval and Wear Simulator Study. International Journal of Biomaterials, 2009, Article ID: 185456. https://doi.org/10.1155/2009/185456

[34] Lee, Y.-K., Yoo, J.J., Koo, K.-H., Yoon, K.S. and Kim, H.J. (2011) Metal Neck and Liner Impingement in Ceramic Bearing Total Hip Arthroplasty. Journal of Orthopaedic Research, 29, 218-222. https://doi.org/10.1002/jor.21246

[35] Patten, E.W., Atwood, S.A., Van Citters, D.W., Jewett, B.A., Pruitt, L.A. and Ries, M.D. (2010) Delamination of a Highly Cross-Linked Polyethylene Liner Associated 
with Titanium Deposits on the Cobalt-Chromium Modular Femoral Head Follownhg Dislocation. The Journal of Bone and Joint Surgery, 92B, 1306-1311. https://doi.org/10.1302/0301-620X.92B9.24290

[36] Amstutz, H.C. and Clarke, I.C. (1991) Evolution of Hip Arthroplasty. In: Amstutz, H.C., Ed., Hip Arthroplasty, Churchill Livingstone Inc., New York, 1-14.

[37] Paul, J.P. (1976) Force Actions Transmitted by Joints in the Human Body. Proceedings of the Royal Society B: Biological Sciences, 192, 163-172. https://doi.org/10.1098/rspb.1976.0004

[38] Bergmann, G., Deuretzbacher, G., Heller, M., Graichen, F., Rohlmann, A., Strauss, J. and Duda, G.N. (2001) Hip Contact Forces and Gait Patterns from Routine Activities. Journal of Biomechanics, 34, 859-871. https://doi.org/10.1016/S0021-9290(01)00040-9

[39] August, A.C., Aldam, C.H. and Pynsent, P.B. (1986) The McKee-Farrar Hip Arthroplasty. A Long-Term Study. The Journal of Bone and Joint Surgery, 68B, 520-527. https://doi.org/10.1302/0301-620X.68B4.3733823

[40] Walker, P.S., Salvati, E. and Hotzler, R.K. (1974) The Wear on Removed McKee-Farrar Total Hip Prostheses. The Journal of Bone and Joint Surgery, 56, 92-100. https://doi.org/10.2106/00004623-197456010-00011

[41] Walker, P.S. and Gold, B.L. (1971) The Tribology (Friction, Lubrication and Wear) of All-Metal Artificial Hip Joints. Wear, 17, 285-299.

https://doi.org/10.1016/0043-1648(71)90032-9

[42] McKellop, H., Park, S.-H., Chiesa, R., Doorn, P., Lu, B., Normand, P., Grigoris, P. and Amstutz, H. (1996) In Vivo Wear of Three Types of Metal on Metal Hip Prostheses during Two Decades of Use. Clinical Orthopaedics and Related Research, 329, S128-S140. https://doi.org/10.1097/00003086-199608001-00013

[43] Munemoto, M., Grammatopoulos, G., Tanaka, Y., Gibbons, M. and Athanasou, N.A. (2017) The Pathology of Failed McKee-Farrar Implants: Correlation with Modern Metal-on-Metal-Implant Failure. Journal of Materials Science: Materials in Medicine, 28, Article No. 66. https://doi.org/10.1007/s10856-017-5882-y

[44] Kothari, M., Bartel, D.L. and Booker, J.F. (1996) Surface Geometry of Retrieved McKee-Farrar Total Hip Replacements. Clinical Orthopaedics and Related Research, 329, S141-S147. https://doi.org/10.1097/00003086-199608001-00014

[45] Burgett, M.D., Donaldson, T.K. and Clarke, I.C. (2013) Denatured Protein Deposits Identical on Simulator and Explanted Hip Bearings. In: Kurtz, S., Greenwald, A., Mihalko, W. and Lemons, J., Eds., Metal-on-Metal Total Hip Replacement Devices, ASTM International, West Conshohocken, 310-322. https://doi.org/10.1520/STP156020120047

[46] Burgett, M., Myant, C., Cann, P., Clarke, I.C. and Donaldson, T.K. (2013) The Role of Protein Films on Hip Bearings Lubricated with Varied Protein Concentration. Orthopedic Research Society, San Antonio.

[47] Maskiewicz, V.K., Williams, P.A., Prates, S.J., Bowsher, J.G. and Clarke, I.C. (2010) Characterization of Protein Degradation in Serum-Based Lubricants during Simulation Wear Testng of Metal-on-Metal Hip Prostheses. Journal of Biomedical Materials Research Part B: Applied Biomaterials, 94B, 429-440. https://doi.org/10.1002/jbm.b.31671

[48] Anissian, H.L., Stark, A., Good, V., Dahlstrand, H. and Clarke, I.C. (2001) The Wear Pattern in Metal-on-Metal Hip Prostheses. Journal of Biomedical Materials Research, 58, 673-678. https://doi.org/10.1002/jbm.1068

[49] Anissian, L., Stark, A., Gustafson, A., Good, V. and Clarke, I.C. (1999) Met- 
al-on-Metal Bearing in Hip Prosthesis Generates 100-Fold Less Wear Debris than Metal-on-Polyethylene. Acta Orthopaedica Scandinavica, 70, 578-582. https://doi.org/10.3109/17453679908997845

[50] Clarke, C., Good, V., Williams, P., Schroeder, D., Anissian, L., Stark, A., Oonishi, H., Schuldies, J. and Gustafson, G. (2000) Ultra-Low Wear Rates for Rigid-on-Rigid Bearings in Total Hip Replacements. Proceedings of the Institution of Mechanical Engineers, Part H: Journal of Engineering in Medicine, 214, 331-347. https://doi.org/10.1243/0954411001535381

[51] Yamamoto, T., Saito, M., Ueno, M., Hananouchi, T., Tokugawa, Y. and Yonenobu, K. (2005) Wear Analysis of Retrieved Ceramic-on-Ceramic Articulations in Total Hip Arthroplasty: Femoral Head Makes Contact with the Rim of the Socket outside of the Bearing Surface. Journal of Biomedical Materials Research Part B: Applied Biomaterials, 73B, 301-307. https://doi.org/10.1002/jbm.b.30215

[52] Kubo, K., Clarke, I.C., Sorimachi, T., Williams, P.A., Donaldson, T.K. and Yamamoto, K. (2009) Aggressive 3rd-Body Wear Challenge to Highly Crosslinked Polyethylene: A Hip Simulator Model. Wear, 267, 734-742.

https://doi.org/10.1016/j.wear.2009.01.029

[53] Bowsher, J.G., Clarke, I.C., Williams, P.A. and Donaldson, T.K. (2009) What Is a "Normal" Wear Pattern for Metal-on-Metal Hip Bearings? Journal of Biomedical Materials Research Part B: Applied Biomaterials, 91B, 297-308. https://doi.org/10.1002/jbm.b.31403

[54] Manaka, M., Clarke, I.C., Gustafson, A. and Imakiire, A. (2003) Impingement in Ceramic Hip Patient a Retrieval and Wear-Scar Analysis of Femoral Head. In: Ben-Nissan, B., Sher, D., Walsh W., Eds., Key Engineering Materials, Vol. 240-242, Trans Tech Publications Ltd., Zurich-Uetikon, 847-848. https://doi.org/10.4028/www.scientific.net/KEM.240-242.847

[55] Kubo, K., Clarke, I.C., Donaldson, T.K., Lazennec, J.Y., Shishido, T. and Yamamoto, K. (2011) Damage of the Bearing Surface in Retrieved Metal-on-Metal THA: Report of 29 Failure Cases. Orthopaedic Research Society 2011 Annual Meeting, Long Beach, 13-16 January 2011, 1212.

[56] Bowsher, J.G., Donaldson, T.K., Williams, P.A. and Clarke, I.C. (2008) Surface Damage after Multiple Dislocations of a 38-mm-Diameter, Metal-on-Metal Hip Prosthesis. Journal of Arthroplasty, 23, 1090-1096.

https://doi.org/10.1016/j.arth.2007.09.007

[57] Burton, P., Medina, E., Burgett-Moreno, M., Donaldson, T., and Clarke, I. (2015) Biomechanical Alignment of Main Wear-Pattern on MOM Total Hip Replacement. Reconstructive Review, 5, 19-23. https://doi.org/10.15438/rr.5.2.111

[58] Clarke, I.C., et al. (2013) Normal and Adverse Wear Patterns Created In-Vivo on MOM Surfaces-A Retrieval Study Representing Four Vendors. In: Kurtz, S.M. et al., Eds., Metal-on-Metal Total Hip Replacement Devices, ASTM International, West Conshohocken, 157-192. https://doi.org/10.1520/STP156020120049

[59] McPherson, E.J., Clarke, I.C. and Donaldson, T.K. (2012) Lesson Learned from Retrieval Analysis of a Dislocating, Large Diameter MoM Revision THA-A Case Report. Reconstructive Review, 2, 10-14. https://doi.org/10.15438/rr.v2i2.9

[60] Pelt, C.E., Erickson, J., Clarke, I., Donaldson, T., Layfield, L. and Peters, C.L. (2013) Histologic, Serologic, and Tribologic Findings in Failed Metal on Metal Total Hip Arthroplasty: AAOS Exhibit Selection. Journal of Bone \& Joint Surgery, 95, e163.

[61] Howie, D.W., McCalden, R.W., Nawana, N.S., Costi, K., Pearcy, M.J. and Subramanian, C. (2005) The Long-Term Wear of Retrieved McKee-Farrar Metal-on-Metal 
Total Hip Prostheses. Journal of Arthroplasty, 3, 350-357.

https://doi.org/10.1016/j.arth.2004.09.028

[62] Sathasivam, S., et al. (2001) The Effect of Contact Area on Wear in Relation to Fixed Bearing and Mobile Bearing Knee Replacements. Journal of Biomedical Materials Research, 58, 282-290. https://doi.org/10.1002/1097-4636(2001)58:3<282::AID-JBM1018>3.0.CO;2-S

[63] Firkins, P.J., Tipper, J.L., Saadatzadeh, M.R., Ingham, E., Stone, M.H., Farrar, R. and Fisher, J. (2001) Quantitative Analysis of Wear and Wear Debris from Metal-on-Metal Hip Prostheses Tested in a Physiological Hip Joint Simulator. Bio-Medical Materials and Engineering, 11, 143-157.

[64] Park, S., McKellop, H., Lu, B., Chan, F. and Chiesa, R. (1998) Wear Morphology of Metal-Metal Implants: Hip Simulator Tests Compared with Clinical Retrievals. Alternative Bearing Surfaces in Total Joint Replacement. J. Jacobs and T. L. Craig. Fredericksburg, Virginia, ASTM: 129-143.

[65] Wong, W.W., Clarke, I.C., Donaldson, T.K. and Burgett, M. (2013) Surface Roughness of Femoral Heads from Metal-on-Polyethylene Total Hip Arthroplasty Retrieved at over 10 Years. Orthopedic Research Society 2013 Annual Meeting, San Antonio, 26-29 January 2013, 1783.

[66] Nguyen, D., et al. (2013) Subluxation of Metal-on-Metal Bearings-Evidence of 2-Body Cup Wear on CoCr Femoral Heads. The Bone \& Joint Journal, 95, 137.

[67] Bengs, B.C., Sangiorgio, S.N. and Ebramzadeh, E. (2008) Less Range of Motion with Resurfacing Arthroplasty than with Total Hip Arthroplasty. Acta Orthopaedica, 79, 755-762. https://doi.org/10.1080/17453670810016812

[68] Elsissy, J.G., et al. (2018) The Significance of Adverse 3rd-Body Wear Damage in the Failure of Metal-on-Metal Bearings Used in Resurfacing and Total-Hip Arthroplasty. Acta Scientific Orthopaedics, 1.

[69] McHugh, D., McHugh, D., Currier, J., Kennedy, F., Collier, J. and Van Citters, D. (2013) Plastic Deformation from Edge Loading is Common on Retrieved Metal-on-Metal Hips and Can Be Predicted with Finite Element Analysis. In: Kurtz, S., Greenwald, A., Mihalko, W. and Lemons, J., Eds., Metal-on-Metal Total Hip Replacement Devices, ASTM International, West Conshohocken, 235-250. https://doi.org/10.1520/STP156020120046

[70] Firkins, P.J., Tipper, J.L., Ingham, E., Stone, M.H., Farrar, R. and Fisher, J. (2001) Influence of Simulator Kinematics on the Wear of Metal-on-metal Hip Prostheses. Proceedings of the Institution of Mechanical Engineers, Part H: Journal of Engineering in Medicine, 215, 119-121. https://doi.org/10.1243/0954411011533481

[71] Jin, Z.M. (2002) Analysis of Mixed Lubrication Mechanism in Metal-on-Metal Hip Joint Replacements. Proceedings of the Institution of Mechanical Engineers, Part H: Journal of Engineering in Medicine, 216, 85-89.

https://doi.org/10.1243/0954411021536225

[72] Amstutz, H.C., Ma, S.M., Jinnah, R.H. and Mai, L. (2004) Revision of Aseptic Loose Total Hip Arthroplasties. Clinical Orthopaedics and Related Research, 420, 2-9. https://doi.org/10.1097/00003086-200403000-00002

[73] Dowson, D. (1995) A Comparative Study of the Performance of Metallic and Ceramic Femoral Head Components in Total Replacement Hip Joints. Wear, 190, 171-183. https://doi.org/10.1016/0043-1648(96)80015-9

[74] Streicher, R.M., Semlitsch, M., Schön, R., Weber, H. and Rieker, C. (1996) Metal-on-Metal Articulation for Artificial Hip Joints: Laboratory Study and Clinical Results. Proceedings of the Institution of Mechanical Engineers, Part H: Journal of 
Engineering in Medicine, 210, 223-232.

https://doi.org/10.1243/PIME_PROC_1996_210_416_02

[75] Rieker, C.B. (2016) Tribology of Total Hip Arthroplasty Prostheses: What an Orthopaedic Surgeon Should Know. EFORT Open Reviews, 1, 52-57.

https://doi.org/10.1302/2058-5241.1.000004

[76] Fisher, J., Jin, Z.M., Tipper, J., Stone, M. and Ingham, E. (2006) Presidential Guest Lecture: Tribology of Alternative Bearings. Clinical Orthopaedics and Related Research, 453, 25-34. https://doi.org/10.1097/01.blo.0000238871.07604.49

[77] Yan, Y., Neville, A., Dowson, D., Williams, S. and Fisher, J. (2010) First In-Situ Measurements to Assess Corrosion Mechanisms for Metal-on-Metal Hip Prostheses with Integrated Hip Simulators. 56th Annual Meeting of the Orthopaedic Research Society, New Orleans, 6-9 March 2010, 2271.

[78] Dowson, D., Hardaker, C., Flett, M. and Isaac, G.H. (2004) A Hip Joint Simulator Study of the Performance of Metal-on-Metal Joints: Part II: Design. Journal of Arthroplasty, 19, 124-130. https://doi.org/10.1016/j.arth.2004.09.016

[79] Van Der Straeten, C. (2017) Current Insights Regarding Metal-on-Metal Bearings for Hip Arthroplasty. Lubricants, 5, 37. https://doi.org/10.3390/lubricants5030037

[80] Karachalios, T., Komnos, G. and Koutalos, A. (2018) Total Hip Arthroplasty: Survival and Modes of Failure. EFORT Open Reviews, 3, 232-239.

https://doi.org/10.1302/2058-5241.3.170068

[81] Logishetty, K., Cobb, J.P. and Allwood, S.M. (2020) Hip Resurfacing-What Is Its Role in Modern Orthopaedics? Bone and Joint 360, 9, 4-9.

https://doi.org/10.1302/2048-0105.91.360742

[82] Matharu, G.S., Judge, A., Murray, D.W. and Pandit, H.G. (2018) Outcomes after Metal-on-Metal Hip Revision Surgery Depend on the Reason for Failure: A Propensity Score-Matched Study. Clinical Orthopaedics and Related Research, 476, 245-258. https://doi.org/10.1007/s11999.0000000000000029

[83] Clarke, I.C., Lazennec, J.Y., Brusson, A., Savisaar, C., Bowsher, J.G., Burgett, M. and Donaldson, T.K. (2014) Risk of Impingement and Third-Body Abrasion with 28-mm Metal-on-Metal Bearings. Clinical Orthopaedics and Related Research, 472, 497-508. https://doi.org/10.1007/s11999-013-3399-3

[84] Donaldson, T.K., Burgett-Moreno, M. and Clarke, I.C. (2015) Excessive Anteversion Leads to Failure at 3 Years Due to Impingement as Evidenced by Twin Notches in Ti6A4V Stem. Reconstructive Review, 5, 25-28.

https://doi.org/10.15438/rr.5.2.110

[85] Lundberg, H.J., Liu, S.S., Callaghan, J.J., Pedersen, D.R., O’Rourke, M.R., Goetz, D.D., Vittetoe, D.A., Clohisy, J.C. and Brown, T.D. (2007) Association of Third Body Embedment with Rim Damage in Retrieved Acetabular Liners. Clinical Orthopaedics and Related Research, 465, 133-139.

https://doi.org/10.1097/BLO.0b013e31815c5a7b

[86] Halim, T., Burgett, M., Donaldson, T.K., Savisaar, C., Bowsher, J. and Clarke, I.C. (2014) Profiling the Third-Body Wear Damage Produced in CoCr Surfaces by Bone Cement, CoCr, and $\mathrm{Ti}_{6} \mathrm{~A}_{14} \mathrm{~V}$ Debris: A 10-Cycle Metal-on-Metal Simulator Test. Journal of Engineering in Medicine, 228, 703-713.

https://doi.org/10.1177/0954411914538782

[87] Doorn, P.F., Campbell, P.A., Worrall, J., Benya, P.D., McKellop, H.A. and Amstutz, H.C. (1998) Metal Wear Particle Characterization from Metal on Metal Total Hip Replacements: Transmission Electron Microscopy Study of Periprosthetic Tissues and Isolated Particles. Journal of Biomedical Materials Research, 42, 103-111. 
https://doi.org/10.1002/(SICI)1097-4636(199810)42:1<103::AID-JBM13>3.0.CO;2M

[88] Underwood, R.J., Zografos, A., Sayles, R.S., Hart, A. and Cann, P. (2012) Edge Loading in Metal-on-Metal Hips: Low Clearance Is a New Risk Factor. Journal of Engineering in Medicine, 226, 217-216. https://doi.org/10.1177/0954411911431397

[89] Kwon, Y.-M., Mellon, S.J., Monk, P., Murray, D.W. and Gill, H.S. (2012) In Vivo Evaluation of Edge-Loading in Metal-on-Metal Hip Resurfacing Patients with Pseudotumours. Bone \& Joint Research, 1, 42-49. https://doi.org/10.1302/2046-3758.14.2000019

[90] Ebramzadeh, E., Campbell, P.A., Takamura, K.M., Lu, Z., Sangiorgio, S.N., Kalma, J.J., De Smet, K.A. and Amstutz, H.C. (2011) Failure Modes of 433 Metal-on-Metal Hip Implants: How, Why, and Wear. Orthopedic Clinics of North America, 42, 241-250. https://doi.org/10.1016/j.ocl.2011.01.001

[91] Langton, D.J., Jameson, S.S., Joyce, T.J., Hallab, N.J., Natu, S. and Nargol, A.V.F. (2010) Early Failure of Metal-on-metal Bearings in Hip Resurfacing and Large-Diameter Total Hip Replacement. A Consequence of Excess Wear. The Journal of Bone and Joint Surgery, British Volume, 92-B, 38-46.

https://doi.org/10.1302/0301-620X.92B1.22770

[92] Langton, D.J., Sidaginamale, R., Lord J.K., Nargol, A.V.F. and Joyce, T.J. (2012) Taper Junction Failure in Large-Diameter Metal-on-Metal Bearings. Bone \& Joint Research, 1, 56-63. https://doi.org/10.1302/2046-3758.14.2000047

[93] John Cooper, H., Della Valle, C.J., Berger, R.A., Tetreault, M., Paprosky, W.G., Sporer, S.M. and Jacobs, J.J. (2012) Corrosion at the Head-Neck Taper as a Cause for Adverse Local Tissue Reactions after Total Hip Arthroplasty. The Journal of Bone \& Joint Surgery, 94, 1655-1661. https://doi.org/10.2106/JBJS.K.01352

[94] Clarke, I.C. and Manley, M.T. (2008) How Do Alternative Bearing Surfaces Influence Wear Behavior? Journal of the American Academy of Orthopaedic Surgeons, 16, S86-S93. https://doi.org/10.5435/00124635-200800001-00018

[95] Clarke, I.C. and Lazennec, J.Y. (2015) Margin-of-Safety Algorithm Used with EOS Imaging to Interpret MHRA Warning for Small-Diameter MOM Hip Arthroplasty. Reconstructive Review, 5, 13-21. https://doi.org/10.15438/rr.5.3.115

[96] Nevelos, J.E., Prudhommeaux, F., Hamadouche, M., Doyle, C., Ingham, E., Meunier, A., Nevelos, A.B., Sedel, L. and Fisher, J. (2001) Comparative Analysis of two Different Types of Alumina-Alumina Hip Protheses Retrieved for Aseptic Loosening. Journal of Bone \& Joint Surgery (Br), 83-B, 998-603.

[97] McKellop, H., Rostlund, T., Ebramzadeh, E., Ebramzadeh, E. and Sarmiento, A. (1996) Wear of Titanium 6-4 Alloy in Laboratory Tests and in Retrieved Human Joint Replacements. In: Brown, S. and Lemons, J., Eds., Medical Applications of Titanium and Its Alloys. The Material and Biological Issues, ASTM International, West Conshohocken, 266-293. https://doi.org/10.1520/STP16085S

[98] Dowling, J.M., Atkinson,J.R., Dowson, D. and Charnley, J. (1978) The Characteristics of Acetabular Cups Worn in the Human Body. The Journal of Bone and Joint Surgery, British Volume, 60-B, 375-382.

https://doi.org/10.1302/0301-620X.60B3.681413

[99] Isaac, G.H., Atkinson, J.R., Dowson, D., Kennedy, P.D. and Smith, M.R. (1987) The Causes of Femoral Head Roughening in Explanted Charnley Hip Prostheses. Engineering in Medicine, 16, 167-173. https://doi.org/10.1243/EMED_JOUR_1987_016_035_02

[100] Sarmiento, A., Ebramzadeh, E., Gogan, W.J. and McKellop, H.A. (1990) Total Hip 
Arthroplasty with Cement. A Long-Term Radiographic Analysis in Patients who Are Older than Fifty and Younger than Fifty Years. The Journal of Bone and Joint Surgery, 72, 1470-1476. https://doi.org/10.2106/00004623-199072100-00007

[101] Charnley, J. (1972) The Long-Term Results of Low-Friction Arthroplasty of the Hip Performed as a Primary Intervention. The Journal of Bone and Joint Surgery. British Volume, 54, 61-76. https://doi.org/10.1302/0301-620X.54B1.61

[102] Agins, H.J., Alcock, N.W., Bansal, M., Salvati, E.A., Wilson Jr., P.D., Pellicci, P.M. and Bullough, P.G. (1988) Metallic Wear in Failed Titanium-Alloy Total Hip Replacements. A Histological and Quantitative Analysis. The Journal of Bone and Joint Surgery, 70, 347-356. https://doi.org/10.2106/00004623-198870030-00005

[103] Jasty, M., Bragdon, C.R., Lee, K., Hanson, A. and Harris, W.H. (1994) Surface Damage to Cobalt-Chrome Femoral Head Prostheses. The Journal of Bone and Joint Surgery, British Volume, 76B, 73-77. https://doi.org/10.1302/0301-620X.76B1.8300686

[104] Kligman, M., Furman, B.D., Padgett, D.E. and Wright, T.M. (2007) Impingement Contributes to Backside Wear and Screw-Metallic Shell Fretting in Modular Acetabular Cups. Journal of Arthroplasty, 22, 258-264. https://doi.org/10.1016/j.arth.2005.01.025

[105] Tikekar, N.M., et al. (2015) Bearing-Foreign Material Deposition on retrieved Co-Cr heads: Composition and Morphology. BioMed Research International, 2015, Article ID: 967278. https://doi.org/10.1155/2015/967278

[106] Oparaugo, P.C., Clarke, I.C., Malchau, H. and Herberts, P. (2001) Correlation of Wear Debris-Induced Osteolysis and Revision with Volumetric Wear-Rates of Polyethylene: A Survey of 8 Reports in the Literature. Acta Orthopaedica Scandinavica, 72, 22-28. https://doi.org/10.1080/000164701753606644

[107] Jones, D.A., Lucas, H.K., O’Driscoll, M., Price, C.H. and Wibberly, B. (1975) Cobalt Toxicity after McKee Hip Arthroplasty. The Journal of Bone and Joint Surgery, British Volume, 57-B, 289-296. https://doi.org/10.1302/0301-620X.57B3.289

[108] Pandit, H., Glyn-Jones, S., McLardy-Smith, P., Gundle, R., Whitwell, D., Gibbons, C.L.M., Ostlere, S., Athanasou, N., Gill, H.S. and Murray, D.W. (2008) Pseudotumours Associated with Metal-on-Metal Hip Resurfacings. The Journal of Bone and Joint Surgery, British Volume, 90-B, 847-851. https://doi.org/10.1302/0301-620X.90B7.20213

[109] Glyn-Jones, S., Pandit, H., Kwon, Y.-M., Doll, H., Gill, H.S. and Murray, D.W. (2009) Risk Factors for Inflammatory Pseudotumour Formation Following Hip Resurfacing. The Journal of Bone and Joint Surgery, British Volume, 91-B, 1566-1574. https://doi.org/10.1302/0301-620X.91B12.22287

[110] Walker, P.S. and Gold, B.L. (1971) The Tribology (Friction, Lubrication and Wear) of All-Metal Artificial Hip Joints. Wear, 17, 285-299.

https://doi.org/10.1016/0043-1648(71)90032-9

[111] McKellop, H., Park, S.-H., Chiesa, R., Doorn, P., Lu, B., Normand, P., Grigoris, P. and Amstutz, H. (1996) In Vivo Wear of Three Types of Metal on Metal Hip Prostheses during Two Decades of Use. Clinical Orthopaedics and Related Research, 329, S128-S140. https://doi.org/10.1097/00003086-199608001-00013

[112] Iida, H., et al. (1999) Metallosis Due to Impingement between the Socket and the Femoral Neck in a Metal-on-Metal Bearing Total Hip Prosthesis. A Case Report. The Journal of Bone and Joint Surgery, 81, 400-403. https://doi.org/10.2106/00004623-199903000-00013 
[113] Yamamoto, K., Shishido, T., Tateiwa, T., Katori, Y., Masaoka, T., Imakiire, A. and Clarke, I. (2004) Failure of Ceramic THR with Liner Dislocation-A Case Report. Acta Orthopaedica Scandinavica, 75,500-502. https://doi.org/10.1080/00016470410001312-1

[114] Kubo, K., et al. (2009) Wear Mapping Analysis with Retrieval 28mm CoCr-CoCr Hip Bearings-11 Years Experience. The Bone \& Joint Journal, 92-B, 734-742.

[115] Nguyen, D., Burgett, M., Halim, T., Donaldson, T. and Clarke, I.C (2013) Debris Impact Zones in Metal-on-Metal Bearings: A New 'Donga' Insight. The Journal of Bone and Joint Surgery, British Volume, 95-B, 137.

[116] Halim, T., Clarke, I.C., Burgett-Moreno, M.D., Donaldson, T.K., Savisaar, C. and Bowsher, J.G. (2015) A Simulator Study of Adverse Wear with Metal and Cement Debris Contamination in Metal-on-Metal (MOM) Hip Bearings. Bone \& Joint Research, 4, 29-37. https://doi.org/10.1302/2046-3758.43.2000332

[117] McKellop, H., et al. (1981) Friction and Wear Properties of Polymer, Metal, and Ceramic Prosthetic Joint Materials Evaluated on a Multichannel Screening Device. Journal of Biomedical Materials Research, 15, 619-653. 


\section{Definition of Terms}

2D: Two dimensional

3D: Three dimensional

ASR: Articular Surface Replacement (Depuy/J\&J)

BHUK: Bristol Hospital, UK

BHR: Birmingham Hip Replacement (Smith and Nephew)

BTP: Black tissue plane

CEM-cup: Cemented cup

CEM-THA: Cemented total hip arthroplasty

CIA: Cup inclination angle

CLO: Cup lift-off angle at hip subluxation

COC: Ceramic-on-ceramic

CoCr: Cobalt chromium alloy

ECD: Equivalent circle diameter for assessment of debris

E/L: Edge loading

F/F: Fluid film lubrication

HS: Hip-subluxation angle

LLUMC: Loma Linda University Medical Center, Dept. Orthopaedics, Loma Linda MOSU: Materials-Science and Orthopaedic Depts, Ohio State University

MOM: Metal-on-metal

MOP: Metal-on-plastic

MWA: MWZ area normalized to femoral-head area

MWZ: Main-wear zone (on head and cup)

$\mathrm{N}$ : Width of femoral neck at impingement

$\mathrm{N}_{\mathrm{d}}$ : Notched neck, distal

$\mathrm{N}_{\mathrm{p}}$ : Notched neck, proximal

NC-cup: Non-cemented cup

NC-THA: Non-cemented total hip arthroplasty

NJR: National Joint Registry

NWZ: Non-wear zone

PC: Polar circle (polar-stripes crossing tangentially)

PE: Polyethylene

LPUH: La Pitié-Salpêtrière University Hospital, Dept. Orthopaedics, Paris

PWZ: Peripheral wear zone

$\mathrm{R}$ : Resultant hip-joint force

ROM: Range of motion

RA: Resurfacing arthroplasty

RSS: Repetitive Sub-clinical Subluxation

SEM: Scanning electron microscopy

SIA: Stripe inclination angle

SNHKS: Sydney Northside Hip \& Knee Surgeons, Australia

SWZ: Stripe wear zone

THA: Total hip arthroplasty 
Ti64: Titanium alloy (Ti6Al4V)

TMU: Tokyo Medical University, Dept. Orthopaedics, Tokyo

UK: United Kingdom

WLI: White-light interferometry (surface roughness data)

Z: Narrow MWZ width on superolateral femoral head

\section{Appendix}

https://www.dropbox.com/sh/5l38thupnwxcg9v/AADjE79nbQD3cjqLXf9KaoO ua? $\mathrm{dl}=0$

https://www.dropbox.com/sh/03azshdkyksze3c/AAB2gv0XBvr5l_6RyR14wigFa? $\underline{\mathrm{dl}=0}$ 